\title{
Fatigue crack initiation and propagation relation at notched specimens with welded joints characteristics
}

\author{
Moritz Braun 1,*, Claas Fischer ${ }^{2}$, Jörg Baumgartner ${ }^{3,4}$, Matthias Hecht ${ }^{4}$ and Igor Varfolomeev 5 \\ 1 Hamburg University of Technology, Institute of Ship Structural Design and Analysis, Hamburg, Germany; \\ moritz.br@tuhh.de \\ (Orcid: 0000-0001-9266-1698) \\ 2 TÜV NORD EnSys GmbH \& Co. KG, Hamburg, Germany; cfischer@tuev-nord.de \\ (Orcid: 0000-0002-6028-6085) \\ 3 Technical University of Darmstadt, Mechanical Engineering Department, Research Group System \\ Reliability, Adaptive Structures, and Machine Acoustics SAM; joerg.baumgartner@sam.tu-darmstadt.de \\ 4 Fraunhofer LBF, Darmstadt, Germany; joerg.baumgartner@lbf.fraunhofer.de \\ (Orcid: 0000-0002-0225-275X) \\ 5 Fraunhofer IWM, Freiburg, Germany; igor.varfolomeev@iwm.fraunhofer.de \\ * Correspondence: moritz.br@tuhh.de; Tel.: +49-40-42878-6091
}

\begin{abstract}
The fatigue life of welded joints under cyclic loading is a complex process that can be roughly divided into fatigue crack initiation, crack propagation and final fracture. Usually, these phases are evaluated separately. Several methods are available to estimate the extent of the different phases in welded components, such as stress-based fatigue concepts for crack initiation or linear elastic fracture mechanics for crack propagation; however, distinguishing these phases in welded components is a complex procedure and often relies on assumptions such as transition crack sizes. The objective of this study is to investigate the relationship between fatigue crack initiation and propagation in welded joints using artificially notched specimens with welded joints characteristics of different notch acuity (different radii and opening angle). The experiments show that the investigated relationship basically depends on the notch acuity, the load level and the stress ratio.
\end{abstract}

Keywords: notch fatigue analysis; finite element analysis; fracture mechanics; stress gradient; notch acuity; S-N curves; statistical methods; artificial notches

Nomenclature:

\begin{tabular}{|c|c|l|}
\hline Symbol & Unit & Description \\
\hline$a_{l c}$ & $\mathrm{~mm}$ & Length of a through-thickness crack \\
\hline$a_{s c i}, a_{0}$ & $\mathrm{~mm}$ & Short crack length and initial crack depth \\
\hline $\mathrm{BM}$ & - & Base material \\
\hline$c_{\text {sci }}, c_{0}$ & $\mathrm{~mm}$ & Short crack length and initial half crack length on the surface \\
\hline$C_{i}$ & - & Material parameters in crack growth equation \\
\hline$C V$ & - & Coefficient of variation \\
\hline$d$ & $\mathrm{~mm}$ & Notch depth \\
\hline$f$ & $\mathrm{~Hz}$ & Test frequency \\
\hline$f\left(L_{r}\right)$ & - & Plasticity correction factor \\
\hline$f\left(R_{n}\right)$ & - & Nominal stress ratio correction factor \\
\hline $\mathrm{HAZ}$ & - & Heat-affected zone \\
\hline$H V$ & - & Vickers hardness \\
\hline$k$ & - & Slope of the S-N curve at $N<N_{k}$ \\
\hline$k^{*}$ & - & Slope of the S-N curve at $N>N_{k}$ \\
\hline$k_{\text {mean }}$, & - & $\begin{array}{l}\text { Mean and standard deviation of the slope of S-N curve in the high } \\
\text { cycle fatigue regime }\left(N \leq N_{k}\right) \text { obtained from bootstrapping }\end{array}$ \\
\hline$k_{s t d}$ & &
\end{tabular}




\begin{tabular}{|c|c|c|}
\hline $\begin{array}{c}K_{J, \max } \\
K_{J, \min } \\
\Delta K_{J}\end{array}$ & $\operatorname{MPa} \sqrt{m}$ & $\begin{array}{l}\text { Maximum and minimum stress intensity factor, and stress intensity } \\
\text { factor range including plasticity correction }\end{array}$ \\
\hline $\begin{array}{l}K_{\max } \\
K_{\min }, \Delta K\end{array}$ & $\mathrm{MPa} \sqrt{m}$ & $\begin{array}{l}\text { Maximum and minimum stress intensity factor, and stress intensity } \\
\text { factor range }\end{array}$ \\
\hline$K_{t}$ & - & Stress concentration factor \\
\hline$L_{r}, \Delta L_{r}$ & - & Plasticity parameter and its range \\
\hline$N_{F C G}$ & - & Cycles spend in crack propagation \\
\hline$N_{G}$ & - & Maximum number of cycles for which a test is considered a runout \\
\hline$N_{f}, N_{f, \exp }$ & - & Cycles to fracture and experimental cycles to fracture \\
\hline $\begin{array}{c}N_{\text {sci }} \\
N_{\text {sci,exp }} \\
N_{\text {sci,pre }}\end{array}$ & - & $\begin{array}{l}\text { Cycles to short crack initiation, respective experimental and predicted } \\
\text { values }\end{array}$ \\
\hline $\begin{array}{c}N_{l c i}, \\
N_{l c i, \exp }, \\
N_{l c i, p r e}\end{array}$ & - & $\begin{array}{l}\text { Cycles to long crack initiation, respective experimental and predicted } \\
\text { values }\end{array}$ \\
\hline$N_{k}$ & - & Cycles at the knee point \\
\hline$R_{K}, R_{K_{J}}$ & - & Stress intensity ratio related to $\Delta K$ and $\Delta K_{J}$ \\
\hline$R_{\text {notch }}$ & $\mathrm{mm}$ & Stress ratio of local stresses \\
\hline$R_{m}, R_{p 0.2}$ & $\mathrm{MPa}$ & Material ultimate strength and yield strength \\
\hline$r$ & $\mathrm{~mm}$ & Radius of notch \\
\hline $\begin{array}{c}r_{x y \prime} \\
r_{\text {Pearson' }} \\
r_{\text {Spearman }}\end{array}$ & - & $\begin{array}{l}\text { Correlation coefficient, Pearson correlation coefficient, and Spearman's } \\
\text { rank correlation coefficient }\end{array}$ \\
\hline$P$ & - & Probability of survival \\
\hline$R$ & - & Stress ratio of nominal stresses \\
\hline std & - & Standard deviation \\
\hline$t$ & $\mathrm{~mm}$ & Specimen thickness \\
\hline$T_{S}$ & - & Measure for scatter ratio in stress direction \\
\hline$x$ & $\mathrm{~mm}$ & Distance from the notch root in crack growth direction \\
\hline$w$ & $\mathrm{~mm}$ & Specimen width \\
\hline WM & - & Weld metal \\
\hline$\Delta K_{t h}$ & $\mathrm{MPa} \sqrt{m}$ & Threshold of the crack intensity factor range \\
\hline$\Delta \sigma_{n, k}$ & $\mathrm{MPa}$ & Nominal stress range at the knee point \\
\hline$\Delta \sigma_{\text {nom }}$ & $\mathrm{MPa}$ & Nominal stress range \\
\hline$\Delta \sigma_{\text {notch }}$ & $\mathrm{MPa}$ & Stress range at the notch \\
\hline$\Delta \mathrm{J}$ & $\mathrm{N} / \mathrm{mm}$ & Cyclic J-Integral \\
\hline$\sigma_{1}$ & $\mathrm{MPa}$ & Maximum principal stress \\
\hline$\omega$ & $\circ$ & Notch opening angle \\
\hline
\end{tabular}

\section{Introduction}

The fatigue life of engineering structures is a complex process that can be divided into several phases. Simplifying this process, three superordinate phases-crack initiation, fatigue crack propagation, and unstable crack growth-are typically considered for design of engineering structures. In fact, these phases are usually assessed individually. The first phase ends when a small crack has nucleated which is of the size of characteristic microstructure dimensions, e.g., the grain size [1]. The second phase is defined by steady fatigue crack propagation. Both phases are primarily governed by the magnitude of cyclic loads. Finally, the third phase is described by unstable crack propagation when approaching the load carrying capacity of a structures or component. While the first two phases govern the majority of service life, the last phase can be neglected in the fatigue life analysis. 
Typically, different fatigue assessment methods are applied to estimate the length of the fatigue crack initiation and propagation phase, e.g., stress-based fatigue concepts for crack initiation or linear elastic fracture mechanics for crack propagation. Different methods have been developed and are still being developed for a holistic fatigue life assessment; however, distinguishing the different phases for welded components is a complex procedure and often relies on assumptions, such as transition crack sizes [2,3]. This is exacerbated by the fact that the ratio between the number of cycles to crack initiation and propagation is typically influenced by the magnitude of external loads: the lower the applied loading the longer the crack initiation portion [1,4]. Hence, this study aims at shedding light on the relation between fatigue crack initiation and propagation in welded joints using artificially notched specimens with welded joints characteristics. For this purpose, an extensive experimental database is evaluated including 351 welded and non-welded specimens made of constructional steels of various strength level, containing notches with varying notch tip radius, opening angle and notch depth, and positioned in different material zones. The effect and significance of different influencing factors on fatigue crack initiation and propagation, as well as on the shape of stress-life (S-N) curves is assessed both experimentally and numerically.

This paper is organized as follows. In Section 2, background topics are introduced related to fatigue crack initiation and propagation with a focus on welded joints. Section 3 describes the test series and specimens involved in the present analysis, test procedures and details of the crack detection in some of the test specimens. Analysis methods applied for evaluating the test results are described in Section 4. A comparison of fatigue lives obtained experimentally and predicted by the analysis as well as their statistical evaluation are given in Section 5. Finally, the main findings of this study are discussed in Section 6.

\section{Background}

\subsection{Fatigue crack initiation and propagation at notches}

The total fatigue life of a component until failure, $N_{f}$, can be represented by a sequence of the crack initiation and fatigue crack growth (FCG) events, as given by

$$
N_{f}=N_{i}+N_{F C G} \text {. }
$$

The first term in Eq. (1), $N_{i}$, is usually estimated using a material S-N curve, an appropriate multiaxial fatigue criterion together with the information on the local stress gradient in the notch root, the highly loaded area and/or material volume, surface roughness, etc. [1,5-8]. The second term, $N_{F C G}$, can be calculated based on the fracture mechanics methodology, while starting from an initial macroscopic surface crack with a size selected according to either the crack detection limit or some simplified rules. Such an initial crack is often considered to have a semi-elliptical shape with the depth $a_{0}$ and the length $2 c_{0}$. For example, [7] defines the initial fatigue crack with a surface length ranging between $2 c_{0}=0.25$ and $3 \mathrm{~mm}$.

Within the framework of the linear-elastic fracture mechanics, the number of cycles associated with the crack propagation stage can be calculated by numerically integrating an FCG equation of type

$$
d a / d N=f\left(\Delta K, R_{K}, C_{i}\right)
$$

with $\Delta K=K_{\max }-K_{\min }$ being the stress intensity factor range, $R_{K}=K_{\min } / K_{\max }$ the stress intensity ratio, and $C_{i}$ denoting material parameters derived by fitting to experimental data. The number of such parameters depends on the type of equation selected for particular application. For the analysis of the test data presented in Section 3.1, a description of FCG rates is required including the stress ratio effect and a proper estimation of the threshold value, $\Delta K_{t h}$. This is achieved, e.g., by using an FCG equation of the NASGRO type [9].

As the notch stress may exceed the yield strength, the initial surface crack $a_{0} \times 2 c_{0}$ can be completely located within plastically deformed material. Consequently, the applicability of the linear-elastic fracture mechanics and $\Delta K$ as the crack driving force parameter becomes questionable. In such a case, a properly defined cyclic J-integral, $\Delta J,[10-12]$ can be employed instead of $\Delta K$ to 
correlate with fatigue crack growth rates. Engineering estimates of $\Delta J[13,14]$ can be derived based on the reference stress method incorporated in the failure assessment diagram approach [15].

\subsection{Aspects related to welded joints}

Welded joints generally contain fabrication-induced notches that reduce fatigue strength regardless of the presence of other (macro-geometrical) notch effects as well as imperfections. In addition, the S-N curves for welded joints are steeper than those of base metal, which is related to the notch effect. This steep slope that is mostly fixed to $k=3$ in all major rules and recommendations is related to the fact that the crack initiation phase is short, and the majority of the fatigue life is spend in crack propagation. It can be shown that under simplified conditions an integration of the Paris-Erdogan law $\left(d a / d N=C \cdot \Delta K^{m}\right)$ leads to an S-N curve with a slope exponent $k$ equal to the Paris curve exponent $m$ [16].

As mentioned above, a slope of $k=3$ is standard for welded joints and included in all major rules and recommendations; however, in few documents, shallower slopes of $k=3.5$ or $k=4.0$ are recommended for welded details with a low stress concentration, such as high-quality welds or welds with weld reinforcement removed [17]. Another difference between the major guidelines is the position of the knee point. In some documents it is set to $N_{k}=5 \cdot 10^{6}$ cycles $[8,18]$ or to $N_{k}=10^{7}[17,19]$, whereas other documents assume a variable position of the knee point depending on the weld details $[20,21]$.

Typically, cracks initiate from one or more locations in weld transitions, such as weld toes, starting from an imperfection or from the point of highest stress concentration, and retain during their growth approximately a semi-elliptical shape. In welded joints, the weld shape often varies considerably along weld seams [22]. It is thus often required to idealize weld shapes to ease assessment procedures.

Despite the fact that a considerable part of fatigue life relates to the crack propagation, welded joints are typically assessed using stress-based concepts $[18,19,23]$. By this, the design curves already include a variable amount of crack propagation portion that depends on the specimen shape (i.e., the notch acuity); nevertheless, there are dedicated guidelines [24] and numerous studies on fatigue crack growth-based assessments of the fatigue strength of welded joints. Such assessment methods usually assume a small initial crack that initiates fatigue crack growth at small imperfections or stress risers, see Bowness and Lee [25].

\section{Experimental data}

\subsection{Specimens}

For this study, welded joints were manufactured with artificial notches of different notch acuity (different radii and opening angle) to separate the effect of varying notch shape along weld seams from other important influencing factors (loading, geometry and material characteristics) and to determine the effect of those on fatigue crack initiation and propagation, as wells as on the shape of S-N curves. In addition, well documented fatigue data on similar specimens from literature (Fischer, et al. [26], Baumgartner [27]) was included in the evaluation, Table 1 and 2. These specimens show typical weld characteristics: firstly, they have differently sharp notches with a notch opening angle of $0^{\circ} \leq \omega \leq$ $15^{\circ}$ (weld root failure at partially penetration welds), $\omega=135^{\circ}$ (weld toe failure at fillet welds), $\omega=$ $160^{\circ}$ (mild weld toe at butt joint) and $\omega=180^{\circ}$ (butt joints ground flush). Secondly, the notch radius is typically very small but varies strongly depending on the welding process. This fact is considered by using radii down to $r=0.05 \mathrm{~mm}$. The majority of specimens have been machined from MAGwelded butt joints with the notch placed in the heat affected zone (HAZ) or the weld metal (WM), Table 1. These specimens were stress relieved by annealing after welding. Additionally, some specimens have been investigated from non-welded plates, Table 2, referred to as base metal (BM) specimens. Overall, six different steel grades have been considered, with different strength level ranging from S235 to S960. 
Table 1. Overview of artificially notched welded specimens

\begin{tabular}{|c|c|c|c|c|c|c|c|c|c|c|}
\hline $\begin{array}{l}\text { Steel } \\
\text { type }\end{array}$ & & $\begin{array}{c}\text { Opening } \\
\text { Angle } \\
\omega \\
\left.{ }^{\circ}\right]\end{array}$ & $\begin{array}{c}\text { Notch } \\
\text { radius } \\
r \\
{[\mathrm{~mm}]}\end{array}$ & $\begin{array}{l}\text { Notch } \\
\text { depth } \\
d \\
{[\mathrm{~mm}]}\end{array}$ & $\begin{array}{c}\text { Stress } \\
\text { concentration } \\
\text { factor } K_{t} \\
\text { [-] }\end{array}$ & $\begin{array}{c}\text { Width in } \\
\text { crack growth } \\
\text { direction } w \\
\text { [mm] }\end{array}$ & $\begin{array}{c}\text { thickness } \\
t \\
{[\mathrm{~mm}]}\end{array}$ & $\begin{array}{c}\text { Number } \\
\text { of } \\
\text { notches }\end{array}$ & $\begin{array}{c}\text { Nominal } \\
\text { stress } \\
\text { ratio } R\end{array}$ & $\begin{array}{c}\text { Series } \\
\text { number }\end{array}$ \\
\hline \multirow[t]{2}{*}{ S235JR+N } & HAZ & 0 & 0.15 & 3 & 8.33 & 9.5 & 20 & 1 & -1 & 1 \\
\hline & HAZ & 135 & 0.15 & 3 & 5.64 & 9.5 & 20 & 1 & -1 & 2 \\
\hline \multirow[t]{3}{*}{ S355MC } & HAZ & 15 & 0.05 & 5 & 12.3 & 8 & 8 & 2 & 0 & 23 \\
\hline & HAZ & 135 & 0.05 & 5 & 6.55 & 8 & 8 & 2 & 0 & 22 \\
\hline & HAZ & $180^{1}$ & $\infty$ & 5 & $\sim 1$ & 8 & 8 & - & 0 & 24 \\
\hline \multirow[t]{4}{*}{ S355J2+N } & HAZ & 0 & 0.15 & 3 & 8.33 & 9.5 & 20 & 1 & -1 & 5 \\
\hline & HAZ & 135 & 0.15 & 3 & 5.64 & 9.5 & 20 & 1 & -1 & 6 \\
\hline & HAZ & 135 & 0.5 & 3 & 3.82 & 9.5 & 20 & 1 & -1 & 7 \\
\hline & WM & 135 & 0.15 & 3 & 5.64 & 9.5 & 20 & 1 & -1 & 8 \\
\hline \multirow[t]{4}{*}{ S690QL1 } & HAZ & 0 & 0.15 & 3 & 8.33 & 9.5 & 20 & 1 & -1 & 10 \\
\hline & HAZ & 135 & 0.15 & 3 & 5.64 & 9.5 & 20 & 1 & -1 & 11 \\
\hline & WM & 160 & 10 & 10 & 1.44 & 10 & 15 & 2 & -1 & 16 \\
\hline & WM & 0 & 0.15 & 3 & 8.33 & 9.5 & 15 & 1 & -1 & 17 \\
\hline \multirow[t]{5}{*}{ S960QL } & HAZ & 15 & 0.05 & 5 & 12.3 & 8 & 8 & 2 & 0 & 26 \\
\hline & HAZ & 15 & 0.5 & 5 & 4.08 & 8 & 8 & 2 & 0 & 25 \\
\hline & HAZ & 135 & 0.05 & 5 & 6.55 & 8 & 8 & 2 & 0 & 29 \\
\hline & HAZ & 135 & 0.5 & 5 & 3.10 & 8 & 8 & 2 & 0 & 28 \\
\hline & HAZ & $180^{1}$ & $\infty$ & 5 & $\sim 1$ & - & - & - & 0 & 27 \\
\hline
\end{tabular}

${ }^{1}$ Hourglass-type specimens

Table 2. Overview of base material-type specimens

\begin{tabular}{|c|c|c|c|c|c|c|c|c|c|}
\hline Steel type & $\begin{array}{c}\text { Opening } \\
\text { Angle } \\
\omega \\
\left.{ }^{\circ}\right]\end{array}$ & $\begin{array}{c}\text { Notch } \\
\text { radius } \\
r \\
{[\mathrm{~mm}]}\end{array}$ & $\begin{array}{l}\text { Notch } \\
\text { depth } \\
d \\
{[\mathrm{~mm}]}\end{array}$ & $\begin{array}{c}\text { Stress } \\
\text { concentration } \\
\text { factor } K_{t} \\
\text { [-] }\end{array}$ & $\begin{array}{c}\text { Width in } \\
\text { crack } \\
\text { growth } \\
\text { direction } w \\
\text { [mm] }\end{array}$ & $\begin{array}{c}\text { thickness } \\
t \text { [mm] }\end{array}$ & $\begin{array}{c}\text { Number of } \\
\text { notches }\end{array}$ & $\begin{array}{c}\text { Nominal } \\
\text { stress } \\
\text { ratio } R\end{array}$ & $\begin{array}{l}\text { Series } \\
\text { name }\end{array}$ \\
\hline \multirow[t]{2}{*}{$\mathrm{S} 355 \mathrm{~J} 2+\mathrm{N}$} & 135 & 0.15 & 3 & 5.64 & 9.5 & 20 & 1 & -1 & 4 \\
\hline & 0 & 0.15 & 3 & 8.33 & 9.5 & 20 & 1 & -1 & 13 \\
\hline \multirow[t]{4}{*}{ QStE380TM } & 15 & 0.05 & 5 & 12.3 & 8 & 8 & 2 & 0 & 18 \\
\hline & 15 & 0.5 & 5 & 4.08 & 8 & 8 & 2 & 0 & 20 \\
\hline & 135 & 0.05 & 5 & 6.55 & 8 & 8 & 2 & 0 & 19 \\
\hline & 135 & 0.5 & 5 & 3.10 & 8 & 8 & 2 & 0 & 21 \\
\hline \multirow[t]{2}{*}{ S690QL1 } & 0 & 0.15 & 3 & 8.33 & 9.5 & 15 & 1 & -1 & 15 \\
\hline & 160 & 10 & 10 & 1.44 & 10 & 15 & 2 & -1 & 14 \\
\hline
\end{tabular}

Figure 1 shows schematically the specimen geometries employed in this study. These can be divided in two groups: some of the specimens have two symmetrical notches, whereas the others are notched asymmetrically which assures crack initiation at the specimen side with a sharper notch. 


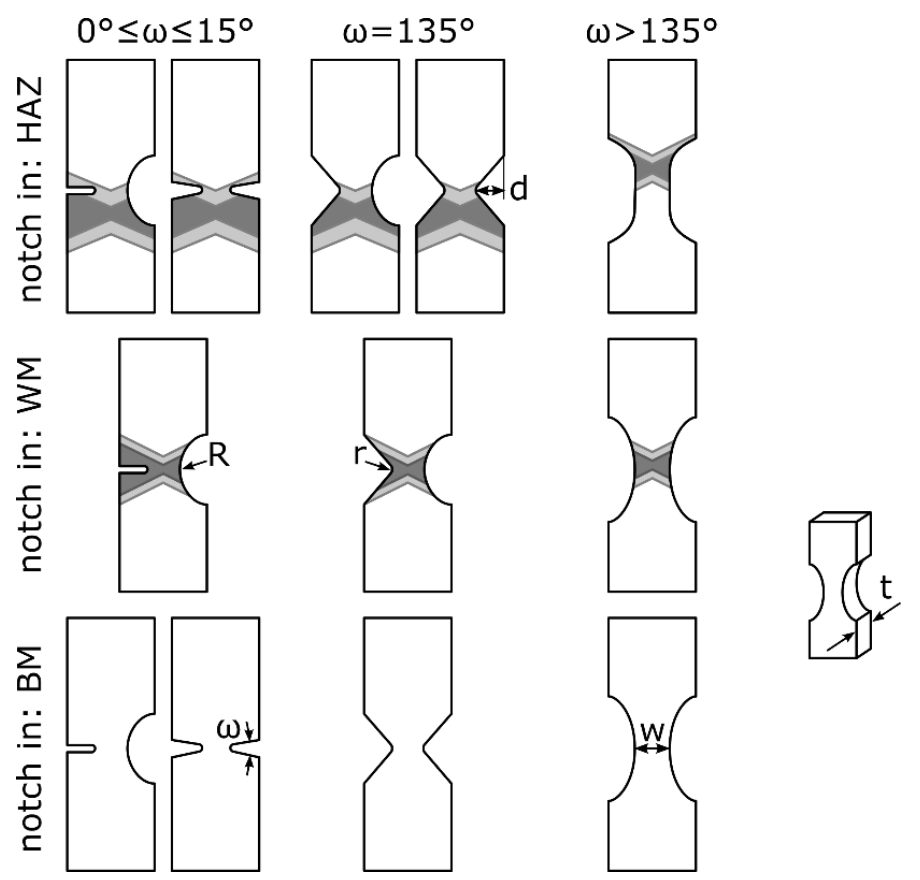

Figure 1. Overview of the specimens used for the evaluation (schematic, not to scale)

\subsection{Specimen characterisation}

To characterize the specimens, measurements of the actual geometry after specimen preparation and of hardness values were performed. The results of the hardness measurements are presented in Figure 2. For the welded joints, measurements were performed either for all relevant zones (BM, HAZ, and WM) and for top, middle and bottom layers (S235JR+N, S355J2+N, S690QL1) or only for the zones where crack initiation occurred (S355MC, QStE380, S960QL).
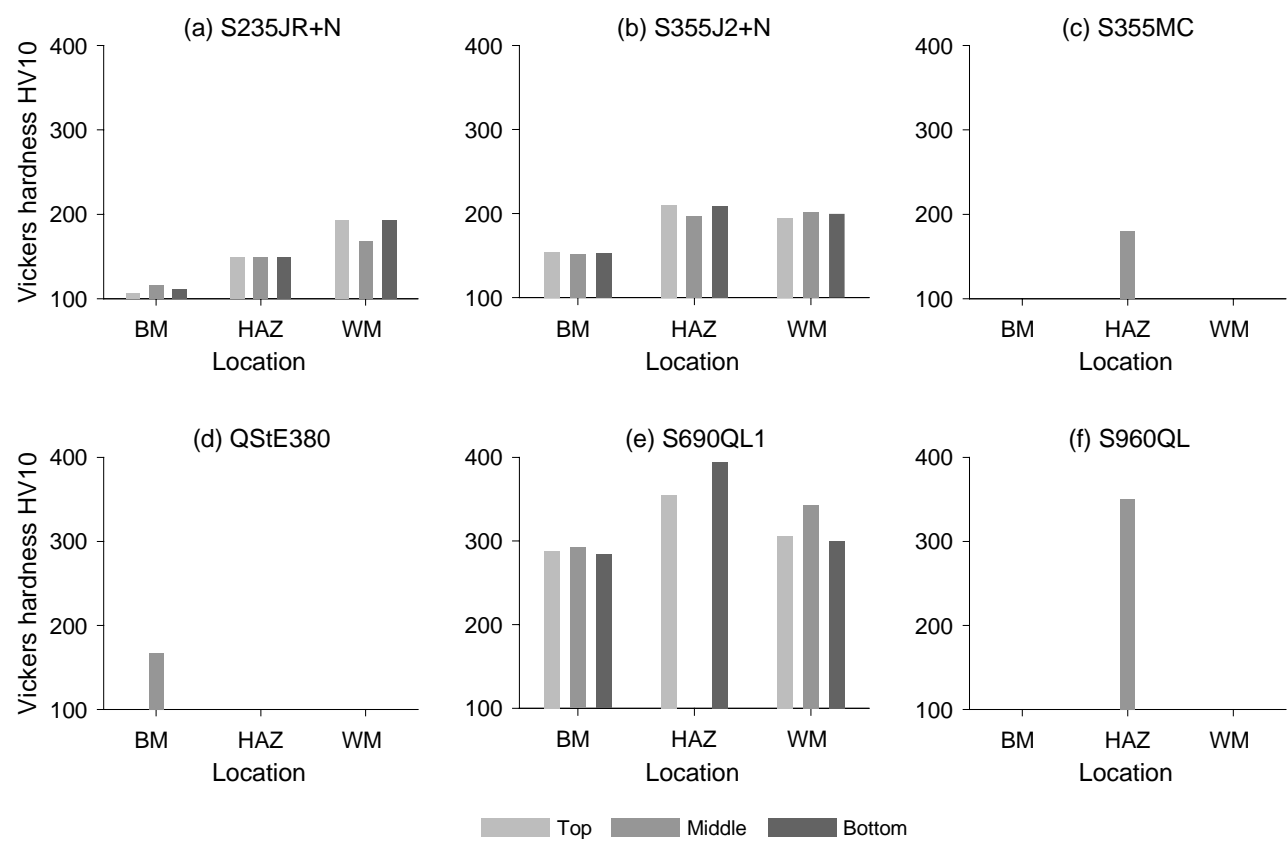

Figure 2. Hardness measurements for the six steel grades with results for the different zones and layers of the welded plates according to ISO 6507-1:2005 [28]

\subsection{Specimen preparation}

The specimens for test series 1-17 (asymmetric notch geometry) were taken from welded plates with reinforcements removed by grinding. For this, two plate strips were joined by manual metal 
active gas welding using an X-butt joint with corresponding weld preparation and several weld passes. Most of the plate strips were fixed in a relatively stiff frame during welding in order to reduce the axial misalignment and the induced angular distortion.

In the next step, the individual specimens of each series were saw cut from the butt-welded plates. The specimens were $400 \mathrm{~mm}$ long, $20 \mathrm{~mm}$ wide and $15 \mathrm{~mm}$ thick. Then the side surfaces in the direction of the welding were polished and acid treated to make the HAZ visible with the aim to place the notch tip in a controlled way. Finally, the intended surface notches were produced by wire electro-erosion, resulting in a net thickness $w=9.5 \mathrm{~mm}$.

In case of relatively large misalignments at a specimen, its ends were additionally milled over $60 \mathrm{~mm}$ length. Thus, high additional stresses caused by clamping the specimens in the testing machine were avoided.

Furthermore, each individual specimen geometry and the existing axial and angular misalignments were measured. Because of misaligned specimens, the notch depth $d$ of the rounding and the notch do vary amongst specimens, but $w$ is fixed. The individual notch depths were measured additionally.

The specimens for test series 18-29 were taken from plates with a thickness of $t=10 \mathrm{~mm}$. Whereas the plate made from QStE380TM was non-welded, the plates made from S355MC and S960QL have been MAG-welded as a butt joint in X-configuration. Both sides of all plates have been ground to reach a final thickness of $t=8 \mathrm{~mm}$. The final specimen geometry was extracted from the plates by wire electro-erosion, Figure 3. As for the test series 1-17, the notch for all specimens of test series 22-29 was positioned in the heat affected zone after etching the plate edges.

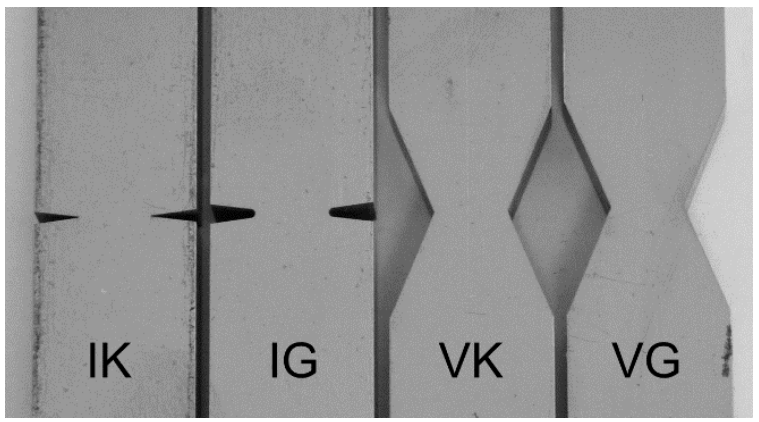

Figure 3. Specimen of test series 18-21

\subsection{Test procedure}

The existing misalignments at specimens of series 1-17 cause additional bending stresses after clamping which interfere with the applied nominal tensile stress. Both stresses are included in the structural stress which was measured by the strain gauge 2 (denoted as „DMS 2 “ in Figure 4) during a static pre-test for each specimen. The gauge was bonded on the specimen surface at a distance of $160 \mathrm{~mm}$ from the end, so that the related signal was not affected by the notch. The opposite strain gauge "DMS 3" was applied to few specimens only to verify the stress distribution over the thickness. Moreover, the strain gauge "DMS 1" was placed to detect crack initiation by measuring an altered strain distribution due to the presence of a crack.

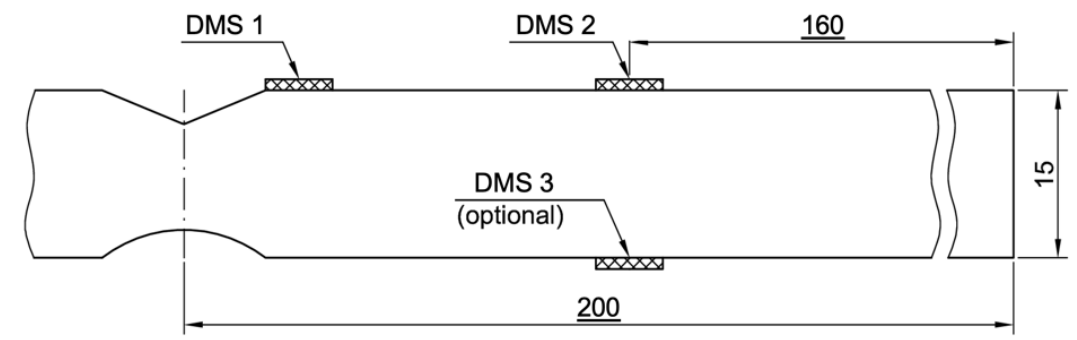

Figure 4. Schematic presentation of the specimen geometry for series 1-17 including the strain gauge positions to detect crack initiation and misalignment-related secondary bending stresses, based on [26] 
The specimens at which the ends are not milled had different local stress ratio $R_{\text {notch }}$ at the notch, which was caused by the angular misalignments. For the consistency of their evaluation in terms of S-N curves, all test results were adjusted to $R_{\text {notch }}=0$. For this purpose, a mean stress correction $f\left(R_{\text {notch }}\right)$ was applied. For notched specimens with $\omega=135^{\circ}$ from Fischer et al. [26], $f\left(R_{\text {notch }}\right)$ was taken from the recommendations of the International Institute of Welding [19] for stress-relieved welded joints. The correction factor used for the sharp notch was experimentally determined by evaluating test results gained under two nominal stress ratios $R=-1$ and $R=0$. The difference with respect to the mean fatigue strength (survival probability of $P=50 \%$ ) at $N=2 \cdot 10^{6}$ cycles is the mean stress effect, being a factor of 1.67 which is experimentally determined. For the base material specimens, the values of $f\left(R_{\text {notch }}\right)$ were estimated according to the FKM guideline [8]. Finally, the corrected structural stress ranges were used as the loading condition in the finite element (FE) analyses, aiming to compute the local fatigue parameter at the notch tip (the stress gradient for instance).

Fatigue testing machines with hydraulic clamps was used in all tests. The tests were performed under a constant force range, at room temperature, at a frequency of about $f=32 \mathrm{~Hz}$ on average. The nominal stress ratio was $R=0$ for the test series $1-17$ and $R=-1$ for the series $18-29$. Each test was conducted until specimen's failure with the related number of cycles denoted by $N_{\mathrm{f}}$; however, a test was stopped between $N_{G}=2 \cdot 10^{6}$ and $N_{G}=1 \cdot 10^{7}$ cycles when neither initial crack was visually detected nor decrease of strain gauge signal was noted. Then the specimen was marked as a run-out and was re-tested to fracture under a larger nominal stress range. In case a crack initiation was detected before $N_{G}$ cycles, the test was continued until failure.

\subsection{Crack detection}

Two methods were applied for crack detection. Crack length foils were bonded to the side surface of specimens of the series 13, 15 and 17. For the series 13, the first resistor strand was located approx. $0.5 \mathrm{~mm}$ below the notch root. The measures were aimed originally catching the crack propagation quantitatively. For the series 15 and 17, a similar method was used with $0.1 \mathrm{~mm}$ spacing between the strands and $0.1 \mathrm{~mm}$ distance to the notch root, see Figure 5(a). For the series 18-29, a digital camera was used for the optical detection of crack initiation and propagation at some of the specimens, see Figure 5 (b). Pictures of the notches have been taken at isochronous timing. For every test specimen, a minimum of 50 pictures were recorded. In order to improve the resolution of the crack initiation detection, a very small layer of a mixture of zinc oxide and glycerin was applied on the notch surface. With this approach crack length on the surface of $0.5 \mathrm{~mm}$ could be made visible.

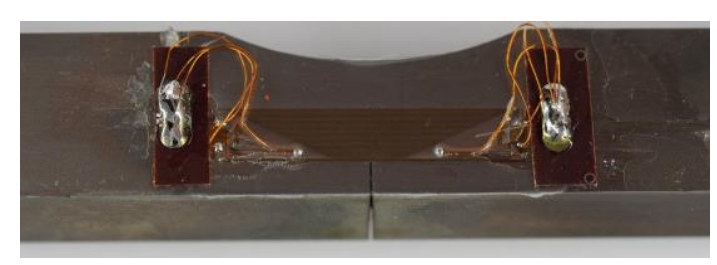

(a)

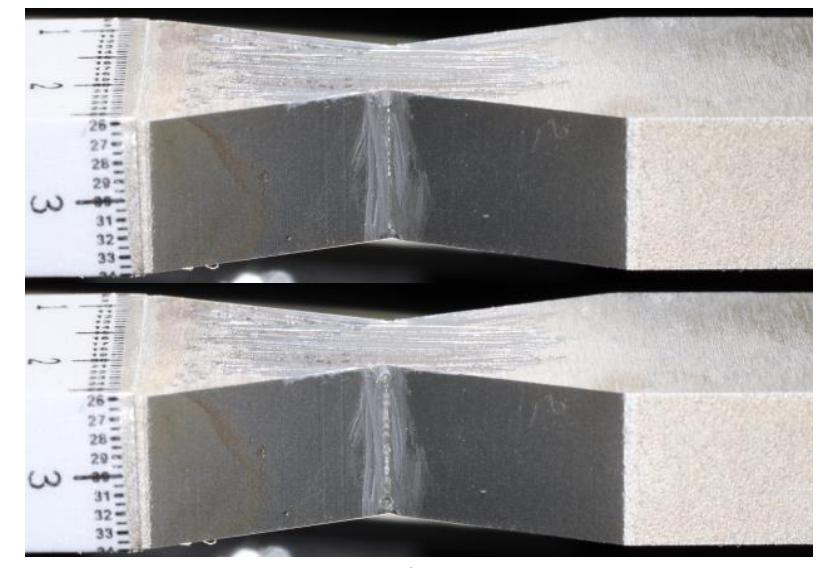

(b)

Figure 5. (a) Specimen with attached crack gauge after removal of weld overfill and wire erosion of notch into the middle of the weld metal and (b) two consecutive pictures from crack detection by photographs (specimen from test series 22) 
The pictures were evaluated visually. As first crack initiation criterion, a crack length on the surface of $1.0 \mathrm{~mm}$ was chosen as small crack initiation. As soon as the first cracks appeared on the side surface of the specimen, the failure criterion of long crack initiation was assigned. Similarly, crack initiation and propagation were monitored and assigned to the different stages by assessing the changing strain signals of the crack detection gauges, see Figure 6.

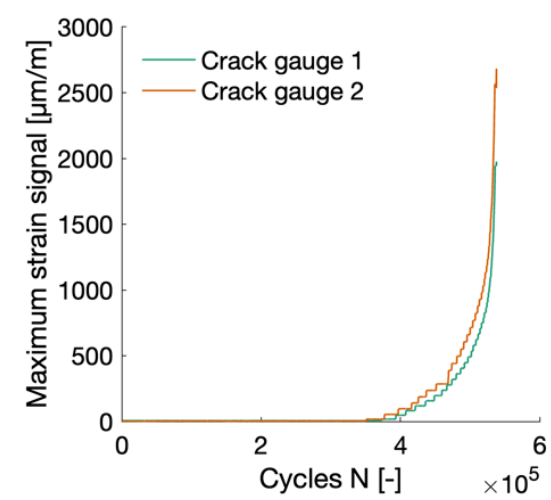

(a)

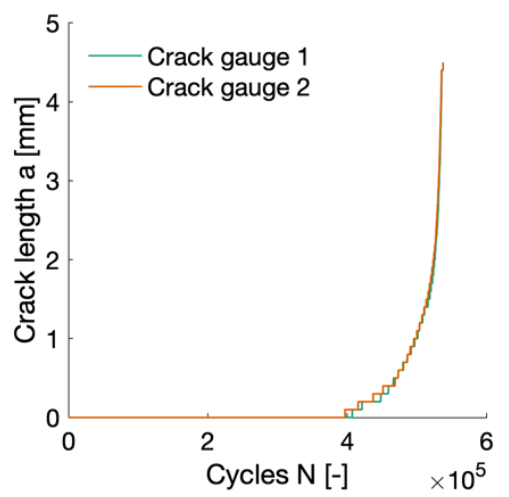

(b)

Figure 6. (a) Strain signal measurement of two crack gauges at top and bottom side over number of cycles for a specimen of the series 15; (b) Crack lengths derived from strain signals.

\subsection{Statistical evaluation of fatigue test results}

In the statistical evaluation, the following parameters of the S-N curves were identified:

- endurable nominal stress at the knee point $\Delta \sigma_{n, k}$,

- number of cycles at the knee point $N_{k}$,

- slope of the S-N curve in the high cycle fatigue regime $\left(N \leq N_{k}\right) k$,

- slope of the S-N curve in the very high cycle regime $\left(N>N_{k}\right) k^{*}$,

- standard deviation std.

Since $k^{*}$ is quite difficult to identify [29], it was set to $k^{*}=45$ according to Sonsino [30].

The statistical evaluation of the S-N curve was performed using the maximum likelihood method [29]. A mathematical best fit S-N curve was calculated, Figure 7 (left), by varying the knee point, Figure 7 (right), and identifying the one with the highest probability, i.e. with the smallest value of the support function [31]. It must be mentioned that this location of the knee point does not necessarily align with the one leading to the smallest standard deviation or the scatter defined as $T_{S}=\Delta \sigma\left(\mathrm{P}_{\mathrm{S}}=90 \%\right) / \Delta \sigma\left(\mathrm{P}_{\mathrm{S}}=10 \%\right)$. Result of the statistical evaluation are the S-N curve parameters for all test series, Table A1.
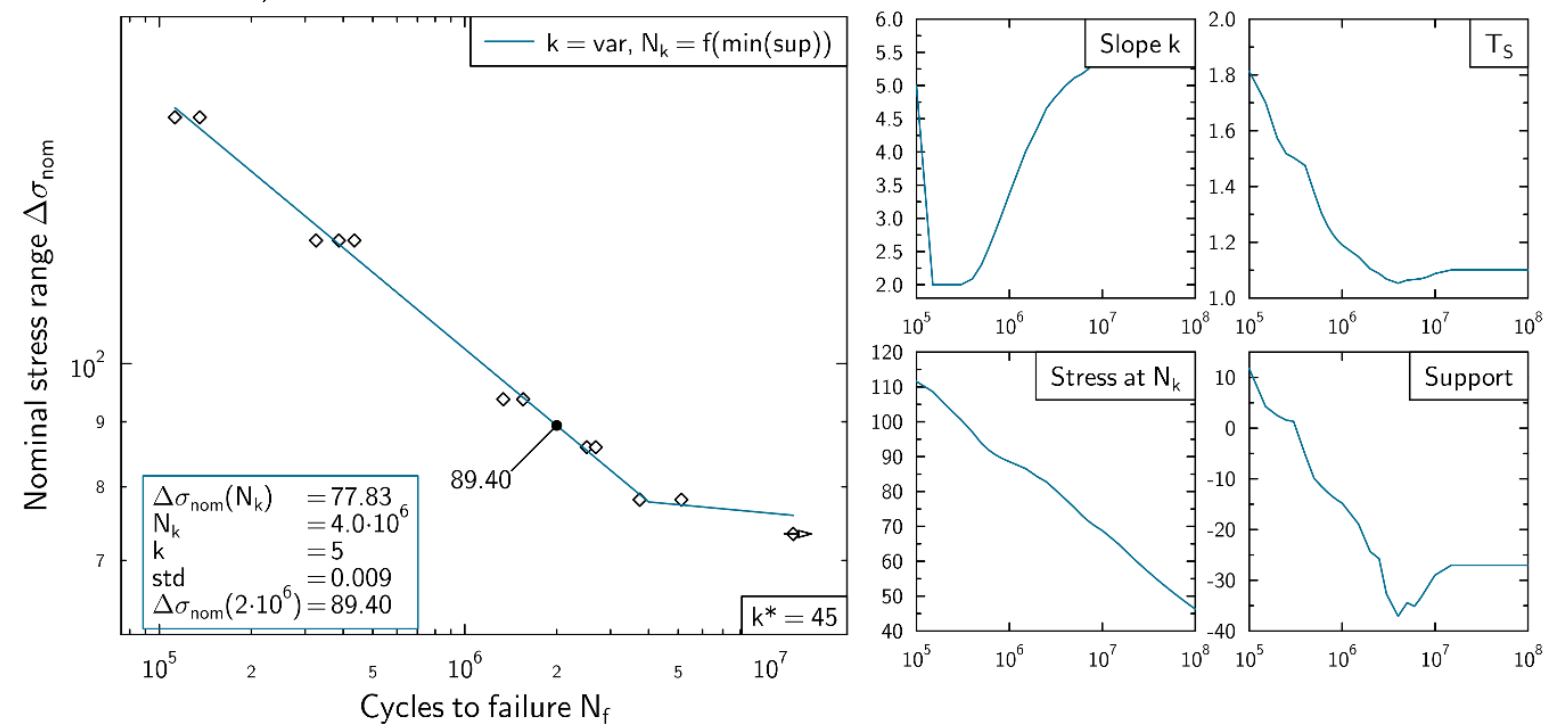

Figure 7. Example of a statistical evaluation of a S-N curve with maximum likelihood (test series 18) 


\section{Methods}

\subsection{Stress calculations}

In order to perform the crack initiation or crack propagation assessment, FE models have been set up based on the recommendations for mesh refinement for different effective stress methods by Braun et al. [32]. Accordingly, 32 elements per $360^{\circ}$ with quadratic shape function are sufficient to accurately determine effective stresses at the notch. As mentioned before, for the specimens affected by misalignment the structural stress at strain gauge "DMS 2" consists of membrane stress and bending stresses that are caused either by clamping or tensioning the axially misaligned specimen with milled ends (secondary bending stress), see Fischer et al. [26]; therefore, the structural stress range applied in the FE analyses equals the membrane stress because the constant clamping stress vanishes and the secondary bending stress is negligible small. In case of milled specimen ends, the clamping stress does not exist and, hence, the applied structural stress range is the interference of membrane and bending stress.

For each specimen, the stress profiles are then obtained from the location of the first principal stress (at the notch root) and in crack growth direction. Examples of stress gradients obtained for all specimens of the series 6 (S355, $\left.r=0.15 \mathrm{~mm}, \omega=135^{\circ}, \mathrm{WM}\right)$, and $1\left(\mathrm{~S} 235, r=0.15 \mathrm{~mm}, \omega=0^{\circ}\right.$, HAZ) are presented in Figure 8. Differences in stress gradients are clearly visible from the comparison, which are due to varying applied nominal stresses; however, the normalized gradients are almost identical. Hence, only one line is visible on the right-hand side in Figure 8.

(a) S355r015w135 WM (Opening angle $\omega=135^{\circ}$ )
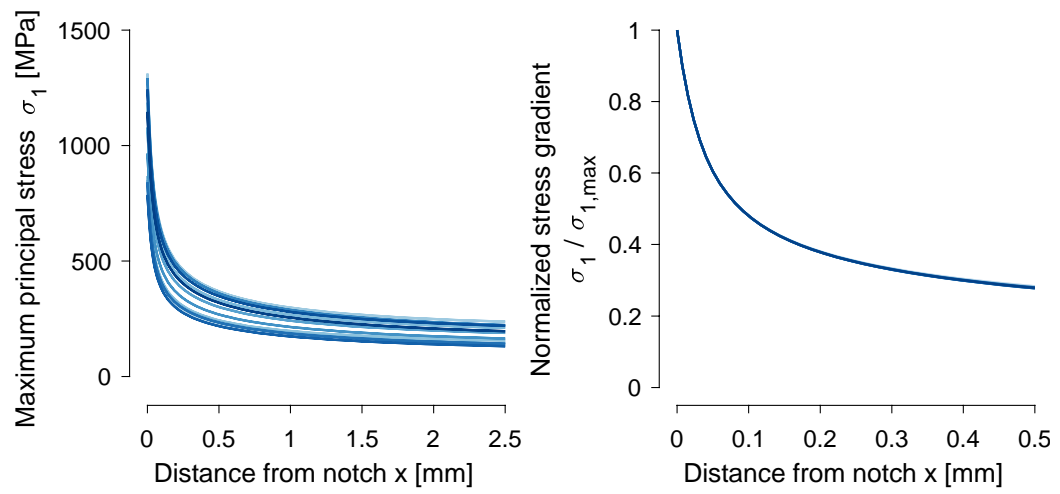

(b) S235r015w0 HAZ (Opening angle $\omega=0^{\circ}$ )
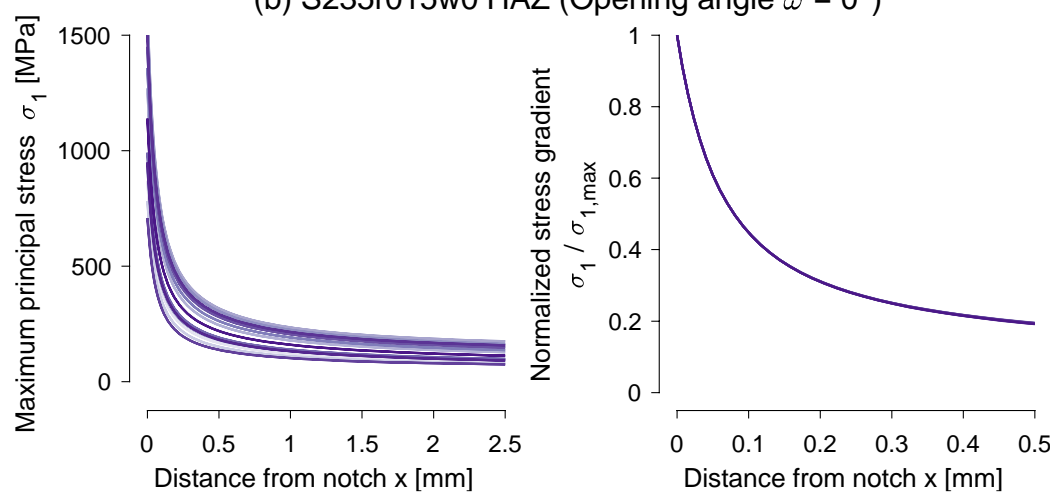

Figure 8. Exemplary stress gradients in crack growth direction of the specimens of series 6 S355, $r=$ $0.15 \mathrm{~mm}, \omega=135^{\circ}, \mathrm{WM}$ (a) and $1 \mathrm{~S} 235, r=0.15 \mathrm{~mm}, \omega=0^{\circ}, \mathrm{HAZ}(\mathrm{b})$, as well as corresponding stress gradients normalized with the maximum principal stress at the notch tip

\subsection{Fatigue crack growth calculations}

To support fracture mechanics calculations, fatigue crack growth data for construction steels were collected describing FCG rates both in the threshold and in the Paris regime, at various stress 
ratios. Among results available in the literature, Zerbst [33] provides comprehensive data for the materials S355NL and S960NL shown as symbols in Figure 9. Note that a considerable number of welded specimens described in Section 3 exhibited misalignment and thus were subjected to superimposed tension and bending loading during fatigue testing (Section 4.1). Consequently, the nominal stress ratio, $R$, varied from specimen to specimen, while the stress intensity ratio, $R_{K}$, additionally varied in the course of crack propagation as a function of the crack depth. To consider this effect, the experimental data [33] were smooth curve fitted by the NASGRO type function [9], as shown by curves in Figure 9. These were employed for all specimens of the same material designation, however, without distinguishing between the base material, weld metal and heat affected zone. Moreover, since no sufficient data were found for other materials specified in Table 1 and Table 2, following assumptions were made:

- FCG curves for S355NL, Figure 9(a), were adopted for S235JR+N, S355MC, S355J2+N and QStE380TM,

- $\quad$ FCG curves for S960NL, Figure 9(b), were adopted for S690QL.

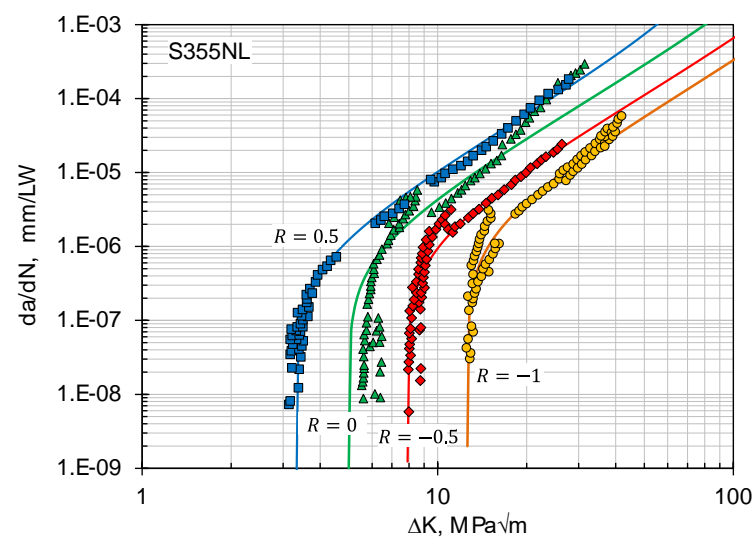

(a)

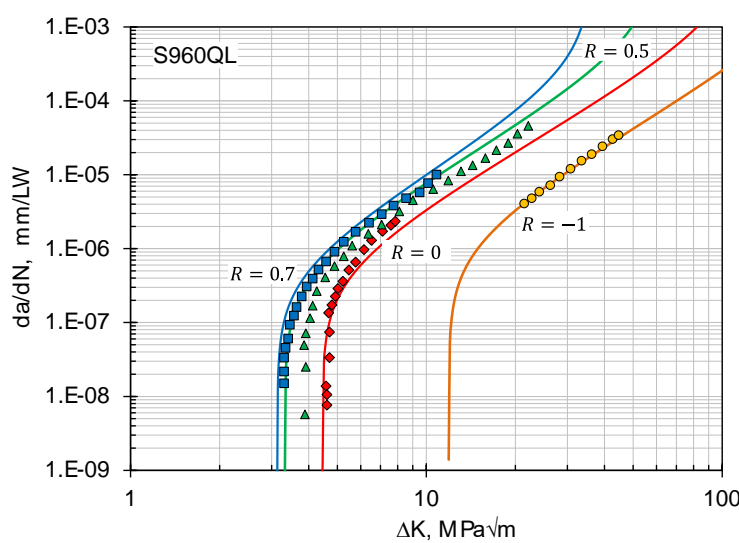

(b)

Figure 9. FCG curves for S355NL (a) and S960QL (b). Symbols: experimental data according to [33], curves: analytical fit according to [9]. Symbols and curves of the same color correspond to the same $R$ value.

In the fatigue crack growth calculations, an initial semi-circular surface crack was considered to be located in the notch root, at the center of the specimen thickness, $t$. Such a crack, referred to as short crack (index " $s c^{\prime}$ ), was assumed to have unique dimensions for all test specimens: the crack depth of $a_{s c i}=0.5 \mathrm{~mm}$, and the crack length of $2 c_{s c i}=1 \mathrm{~mm}$ similar to the recommendation by Radaj et al. [1]. Thereafter, two stages of crack propagation were analyzed. The first one corresponds to the growth of the initial short crack until a complete penetration through the specimen thickness, ending up at $2 c=$ $t$ and $a=a_{l c}$. Here, $a_{l c}$ denotes the depth of a resulting through-thickness, or long, crack. Subsequent crack growth, starting at $a=a_{l c}$ until final fracture, corresponds to the second stage of crack propagation. The total fatigue life associated with fatigue crack propagation, $N_{F C G}$ in Eq. (1), is then determined by

$$
N_{F C G}=N_{s c}+N_{l c}
$$

where $N_{s c}$ and $N_{l c}$ are the load cycles associated with the first and the second stages, respectively. Given the total fatigue life, $N_{f}$, and provided the quantities in the right-hand side of Eq. (3) can be estimated by fracture mechanics calculations, the number of load cycles until short crack and long crack initiation can be deduced from

$$
N_{s c i}=N_{f}-N_{s c}-N_{l c}
$$

and 


$$
N_{l c i}=N_{f}-N_{l c}
$$

respectively.

High stress concentration factors reported in Table 1 and Table 2 suggest that a significant amount of the tested specimens revealed plastic deformations in the notch root, at a potential crack initiation location. As mentioned in Section 2.1, the linear-elastic fracture mechanics methods need to be modified in such a case to account for material yielding. For this purpose, an analytical approach is adopted in the present study as described below.

Given the upper and the lower stress intensity factors in a load cycle, $K_{\max }$ and $K_{\min }$, their plasticity corrected values are calculated based on the FAD methodology:

$$
K_{J, \max }=\frac{K_{\max }}{f\left(L_{r, \max }\right)}, K_{J, \min }=\frac{K_{\min }}{f\left(L_{r, \min }\right)} .
$$

Here, $f\left(L_{r}\right)$ is the failure line according to [15], and $L_{r}$ the plasticity parameter determined from the reference stress or, alternatively, from the plastic limit load for a particular crack configuration. Thereby, the plasticity correction applies only for an open crack: in case of $K_{\min } \leq 0$ or $K_{\min } \leq$ $K_{\max } \leq 0$, the denominator in Eq. (2) is set to $f\left(L_{r}\right)=1$. Accordingly, the following two parameters

$$
\Delta K_{J}=K_{J, \max }-K_{J, \min }, R_{K_{J}}=\frac{K_{J, \min }}{K_{J, \max }} .
$$

substitute the $\Delta K$ and $R_{K}$ values in the fatigue crack growth equation.

Note that this definition of an "effective" stress intensity factor range, $\Delta K_{J}$, differs from those suggested in [13] or [14]. First, it does not involve a crack closure term which estimate is rather ambiguous. Second, it seems that using the whole range $\Delta L_{r}$ instead of $L_{r}$ in Eq. (6) may lead to an overestimation of the crack driving force at $R_{K}<0$ and vice versa at $R_{K}>0$.

When calculating the first FCG stage, $N_{s c}$ or short crack growth, the stress intensity factor and the parameter $L_{r}$ were evaluated using the corresponding solutions for a plate with a semi-elliptical surface crack according to [34] and [35]. The second FCG stage, $N_{l c}$ or long crack growth, was analyzed based on the model of an extended surface crack of a constant depth, and respective $K$ and $L_{r}$ solutions from [36] and [37].

The calculations of the function $f\left(L_{r}\right)$ require the knowledge of the material yield strength, $R_{p 0.2}$, and the ultimate strength, $R_{m}$. Those properties were not available for all material zones and steel grades considered. Therefore and for the sake of consistency, the strength properties were estimated in all cases based on correlations with the hardness HV [38]:

$$
R_{p 0.2}=-90.7+2.876 H V, R_{m}=-99.8+3.734 H V .
$$

The results of hardness measurements are summarized in Figure 2.

\section{Results}

\subsection{Assessment of fatigue test results}

To be able to assess the accuracy of the fatigue crack growth calculations, effects on the measured crack initiation and propagation behavior were first assessed. Typically, the ratio between the number of cycles to crack initiation and fracture is influenced by the magnitude of the applied loading, see Radaj et al. [1] and Murakami [4]. As specimens with a wide range of stress concentration factors $K_{t}$ were tested, the ratio between experimental cycles to short $N_{\text {sci,exp }}$ and long crack initiation $N_{l c i, \text { exp }}$ to the cycles to fracture $N_{f, \text { exp }}$ are plotted over the applied notch stress range $\Delta \sigma_{\text {notch }}$ in Figure 10. The latter is defined as the product of nominal stress $\Delta \sigma_{\text {nom }}$ and stress concentration factor $K_{t}$. All results are corrected to $R_{\text {notch }}=0$ with the aforementioned mean stress correction functions $f\left(R_{\mathrm{n}}\right)$. 
(a) Short fatigue crack initiation to fracture ratio

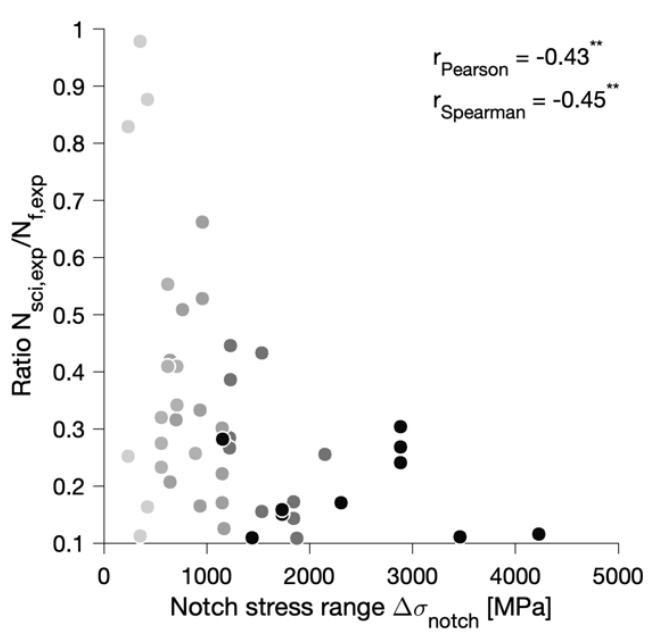

(b) Long fatigue crack initiation to fracture ratio

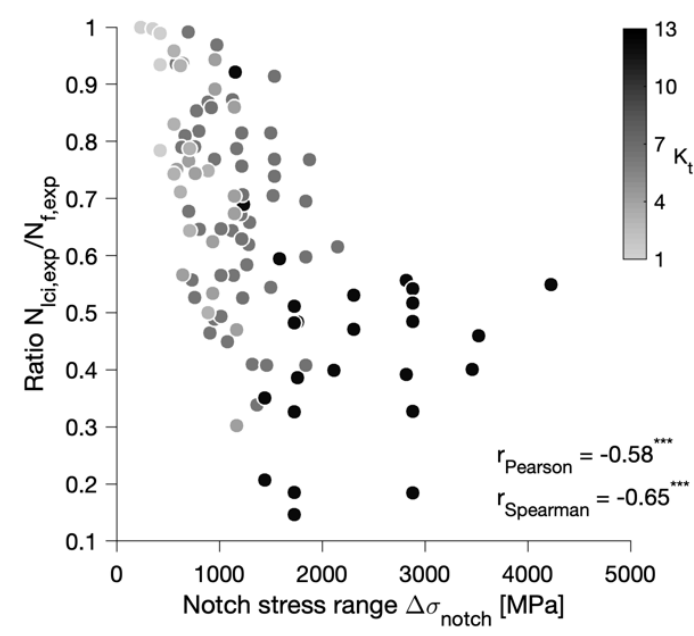

Figure 10. Comparison of ratios between (a) cycles to short or (b) long crack initiation with cycles to fracture (notch stress range mean stress corrected to $R_{\text {notch }}=0$ ).

Two different types of correlation coefficients are determined to assess the statistical interference between the applied notch stress range $\Delta \sigma_{\text {notch }}$ and the ratios $N_{\text {sci,exp }} / N_{f, \exp }$ and $N_{\text {lci,exp }} / N_{f, \text { exp }}$. The first one is the Pearson correlation coefficient, which determines a linear correlation between two variables based on their covariance divided by the product of their standard deviations. The second one is Spearman's rank correlation, which assesses whether there is a monotonic relation between both input parameters. Hence, it is also capable of assessing non-linear relations. Pearson's correlation coefficient is not suitable for such relations. This is an important aspect, as the relation between number of cycles to failure and applied loading follows a power law (Basquin's equation). This effect is expected to be accounted for more effectively by Spearman's rank correlation than by Pearson's correlation.

In addition, Spearman's rank correlation is relatively robust against outliers [39]. Definitions of moderate to strong correlations vary in the literature; however, values above $\left|r_{x y}\right|=0.7$ are often associated with strong correlation and values below $\left|r_{x y}\right|=0.3$ are typically considered weak.

From Figure 10(a), moderate Pearson's and Spearman's type correlations between the ratio $N_{\text {sci,exp }} / N_{f, \text { exp }}$ are observed. In contrast, an almost strong correlation is determined between the ratio $N_{\text {lci,exp }} / N_{f, \text { exp }}$ in Figure 10 (b). This effect is thought to be related to two aspects. First, there is more data available for long crack initiation $N_{l c i, e x p}$, as the crack detection gauges cannot detect a semielliptical surface crack on the surface of the notch and second, it is more difficult to determine a small semi-elliptical crack reliably. This can also be seen by the larger scatter of results for small to moderate notch stress ranges $\Delta \sigma_{\text {notch }}<500 \mathrm{MPa}$ in Figure 10(a)-ranging from almost immediate crack initiation to crack initiation just before final fracture.

In summary, the results agree with the general understanding that the crack initiation portion dominates in the high-cycle fatigue regime whereas crack propagation the medium- and low-cycle fatigue regime, see Radaj et al. [1].

\subsection{Comparison of fatigue test results and fatigue life estimates based on FCG calculations}

Figure 11(a) is a plot of fatigue lives for the notched specimens measured experimentally, $N_{f, \text { exp }}$, and those predicted by fracture mechanics calculations, $N_{F C G, p r e}$. The latter do not include the load cycles $N_{s c i}$ required for short crack initiation and, thus, tend to underestimate the total fatigue life. Indeed, for $77 \%$ of all data, the calculated points are allocated below the 1:1 line in the diagram. At the same time, almost all data are located within a threefold scatter band bounded by the 1:3 and 3:1 lines. An exception is mainly for the tests classified as runouts (no crack initiation), while an initial crack was inevitably assumed in the fracture mechanics calculations. Another exceptional point is 
located above the 1:3 line, in the area of non-conservative prediction, and relates to a S690QL HAZ sample with the notch characteristics $\omega=135^{\circ}, R=0.15 \mathrm{~mm}$, and $K_{t}=5.64$ (test series 11). This outlier can be explained by i) uncertainties in the material data assumed for S690QL and its HAZ, and ii) the fact that the respective sample was tested at a stress level considerably exceeding the yield strength. As a consequence, that sample revealed the shortest lifetime, $N_{f}=10,056$ cycles, of all samples in the test series 11 .

Figure 11(b) compares predicted fatigue lives until short crack initiation, Eq. (4), with the corresponding experimental results. On an average, most data points in the diagram are allocated around the 1:1 line, thus suggesting that the fracture mechanics model reasonably predicts short crack initiation. A large scatter of the results can be explained by numerous uncertainties in the input data and underlying assumptions, e.g., material properties and inaccuracies of their approximation (Figure 9), initial crack size and crack initiation site selected to be fixed for all specimens, deterministic approach adopted in this study. Additional uncertainties may arise due to limited capabilities of the detection of short cracks during the tests. Some of the uncertainties mentioned above are eliminated after a long crack has initiated. This is demonstrated in Figure 11(c) which shows a good agreement between fatigue lives predicted until long crack initiation, Eq. (5), and the related experimental observations.
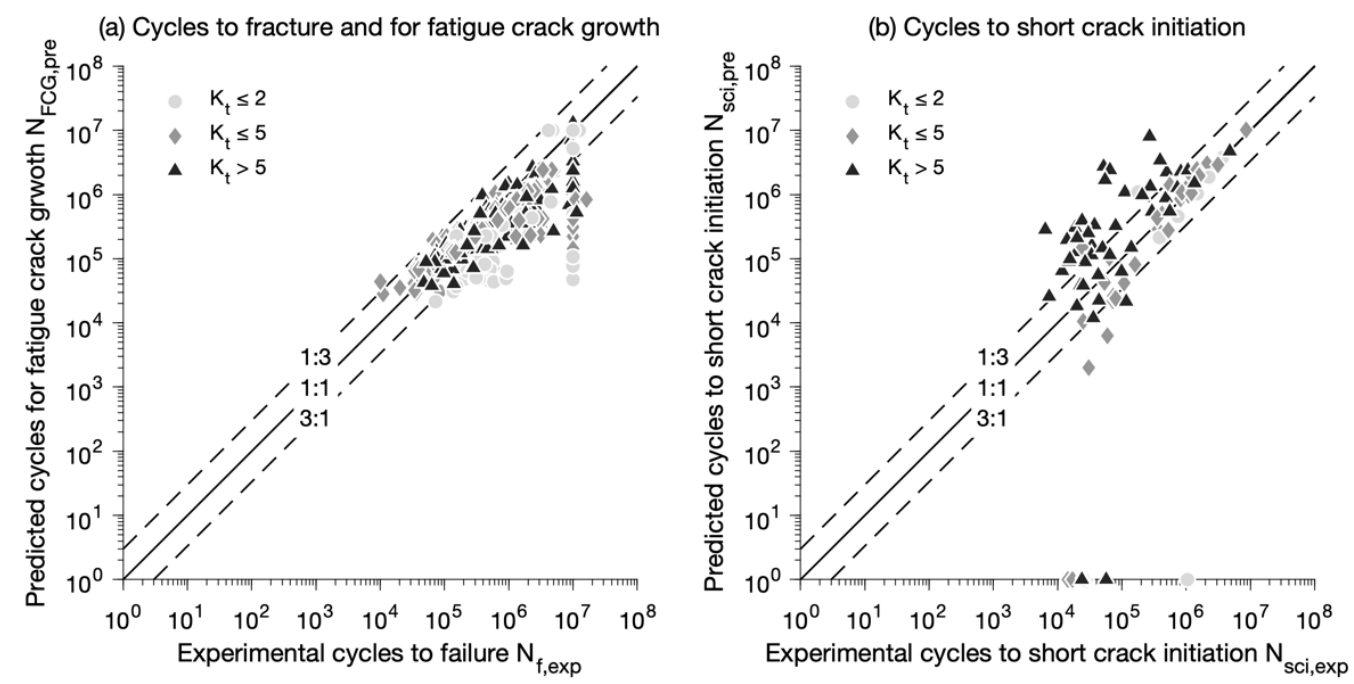

(c) Cycles to long crack initiation

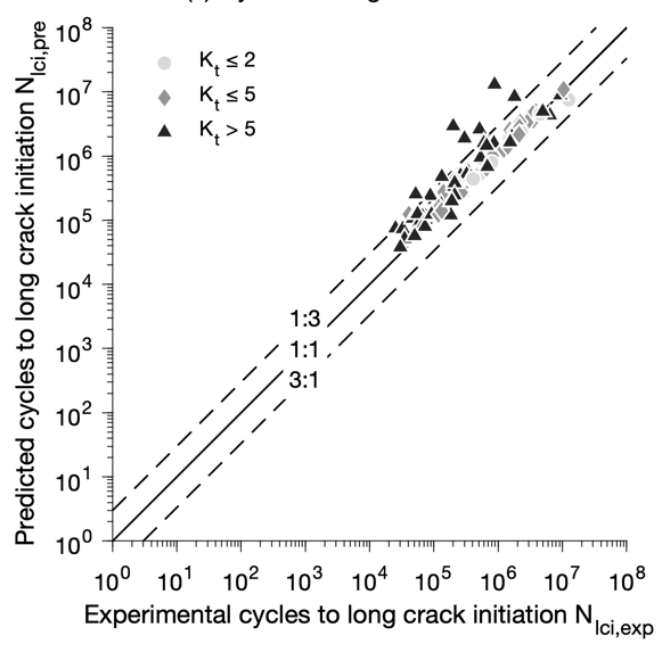

Figure 11. Comparison of (a) cycles to fracture and cycles for fatigue crack growth, (b) cycles to crack initiation and (c) cycles to long crack initiation. 
A different view on the results can be gained by plotting them in an S-N diagram for individual test series, Figure 12. For test series 18 which specimens have a sharp notch $\left(r=0.05 \mathrm{~mm}, \omega=15^{\circ}\right)$ a good correlation between the number of cycles calculated by fracture mechanics and the total fatigue life can be seen. The lifetime is slightly underestimated by a factor of 2 . The factor between the cycles for the failure criterion of long crack initiation and fracture is comparable between fatigue test and calculation; however, the number of cycles to crack initiation $N_{s c i}$ that is derived by subtracting the experimentally determined cycles to fracture from the total cycles spend for crack growth calculated by fracture mechanics deviates by more than a factor of 10 . This underestimation can be seen for the majority of the sharply notch specimens, Figure 11(b). In contrast, a good correlation between experimentally determined and numerically calculated crack initiation cycles can be identified for test series 21 in which specimens with a comparatively mild notch $\left(r=0.5 \mathrm{~mm}, \omega=135^{\circ}\right)$ have been investigated.
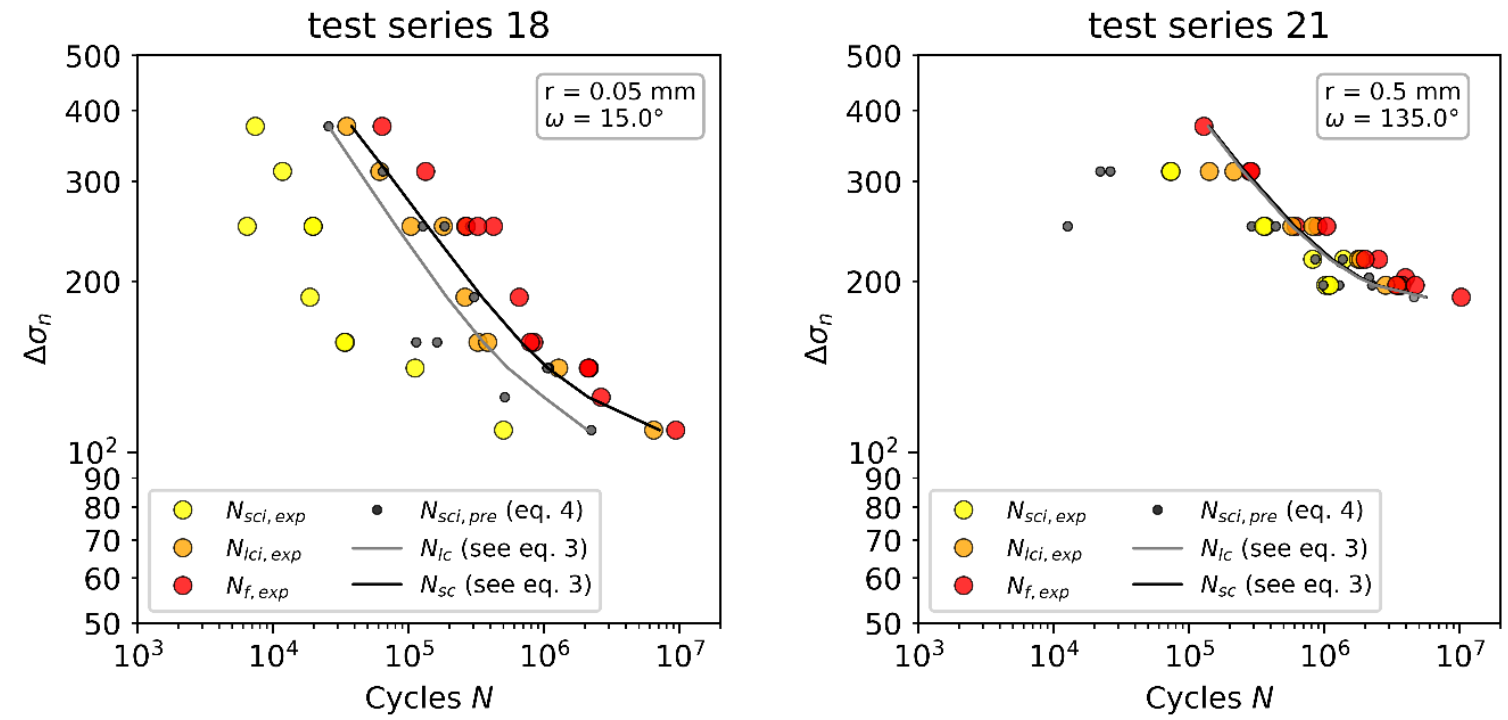

Figure 12. Comparison of S-N data: experimentally derived for three failure criteria, numerical calculated cycles for short crack growth and total crack growth and derived crack initiation cycles.

\subsection{Statistical assessment of influencing factors}

The parameters of the S-N curve have been derived from a statistical evaluation using the maximum likelihood method; however, from this evaluation no measure of the accuracy can be deduced. To test the reliability of the results of the statistical evaluation, a bootstrapping approach was used. For each test series, 1000 resamples with replacement have been evaluated. Each resample had the same number of cycles as the original test series and was again analyzed statistically by maximum likelihood. To avoid unrealistically steep slopes of the S-N curves, the minimum slope was set to $k_{\min }=1$. As a result, $1000 \mathrm{~S}-\mathrm{N}$ curves have been derived for one test series with identified individual values of $\Delta \sigma_{k}, N_{k}$ and $k$. The variation of the S-N curve parameters and subsequently the accuracy of these values can be visualized in distribution plots, Figure 13.

The width of the filled areas in Figure 13 represents the distribution of the parameters $k, N_{k}$ and $\Delta \sigma_{n, a, k}$. A small variation of the parameters is indicated if the distribution has a small height, such as shown for the slope $k$ of test series 1 . A high variation, as identified for example for the slope of test series 2, stands for a high scatter in the S-N data. It indicates that the determined (mean) values might not represent the real parameters. In addition, the derived mean values are plotted with a white dot. The parameters in a range between the 1st and 3rd quartile can be identified by the black line. Next to the distribution of the S-N parameters, also their coefficient of variation $(\mathrm{CV})$ is plotted that shows a standardized measure of the dispersion of the probability distribution. 

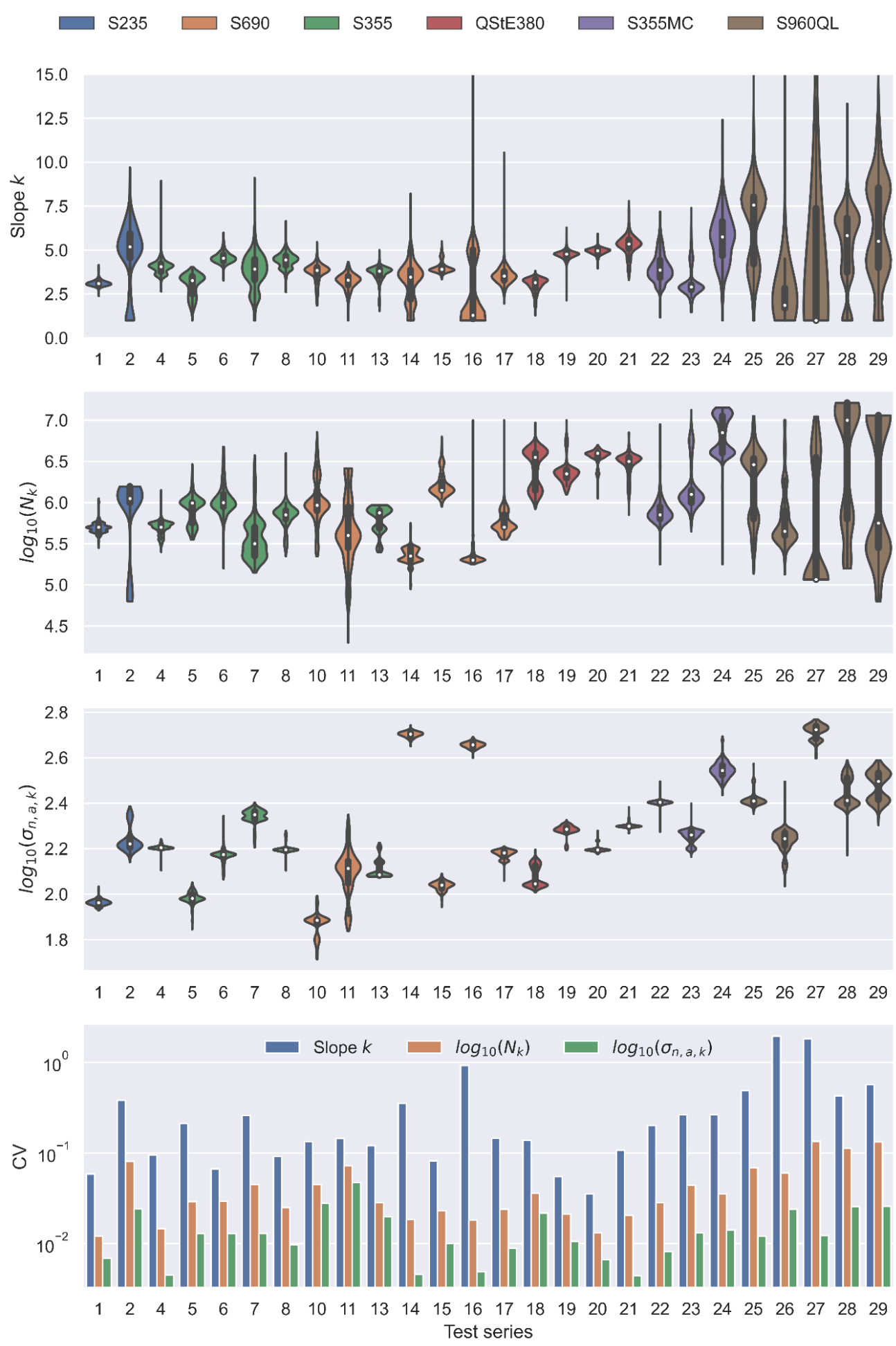

Figure 13. Evaluation of the slope $k$, location of $N_{k}, \sigma_{n, k, a}$ and the coefficient of variation (CV) of all test series determined by bootstrapping (minimum slope was set to $k_{\min }=1$ )

As it can be seen, some test series show quite a low scatter in all parameters $k, N_{k}$ and $\sigma_{n, a, k}$, such as 1,4 or 20 . For some other test series, such as 2,16 or $26-27$, quite a high scatter can be identified. This can directly be attributed to a comparatively high scatter in the original S-N data and small number of overall tests. Even if the values of the slope and the knee point show high variations, the variation of the endurable stresses at the knee point is comparatively low. It is important to mention that the distributions determined by bootstrapping should be interpreted with care since 
they are based only on few data points, the available S-N data; however, the distributions give a good understanding of the reliability of the determined parameters.

In a subsequent step, a correlation analysis between

- shape parameters of the S-N curve $k$ and $N_{k}$,

- geometric properties of the specimens $r$ and $\omega$ and

- stress concentration factor $K_{t}$

has been performed. For this, the average values of the slope and the knee point of all 1000 resamples, $k_{\text {mean }}$ and $N_{\text {mean }}$, as well as their standard deviation, $k_{s t d}$ and $N_{s t d}$, have been calculated.

Again, two different types of correlation coefficients, Pearson's and Spearman's ones, are determined to assess the statistical interference between the parameters of the S-N curve derived by the maximum likelihood method and other influencing factors (geometrical parameters and hardness). The first one is the Pearson correlation coefficient and the second is Spearman's rank correlation, which is capable of assessing non-linear relations. This is an important aspect, as some parameters are typically expected to have a non-linear impact, e.g., notch radius on stress concentration factor. As mentioned before, a correlation above $\left|r_{x y}\right|=0.7$ is often associated with strong correlation and values below $\left|r_{x y}\right|=0.3$ are typically consider weak.

The results for both types of correlation coefficients are presented in Figure 13 as correlation matrices. Therein, the magnitude of correlation is displayed by its color intensity. In other words, darker colors on both sides of the contrasting spectrum are associated with stronger correlations.

(a) Pearson correlation

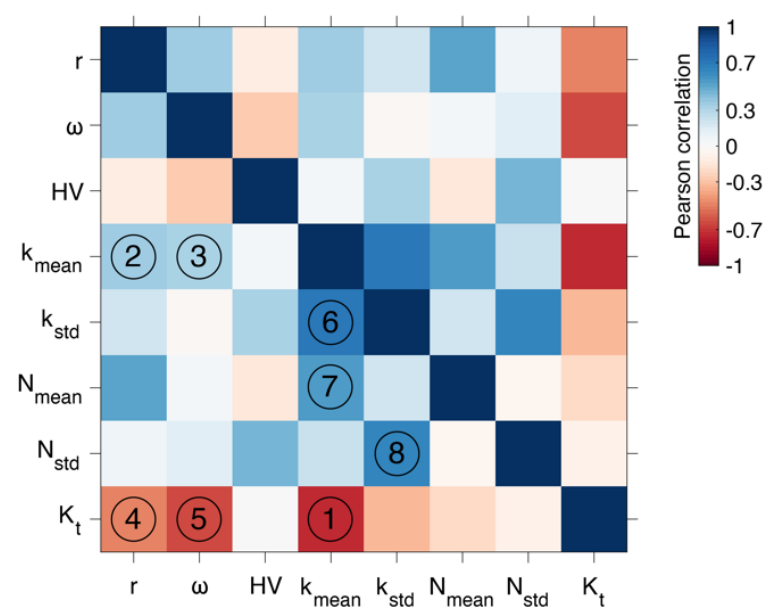

(b) Spearman's rank correlation

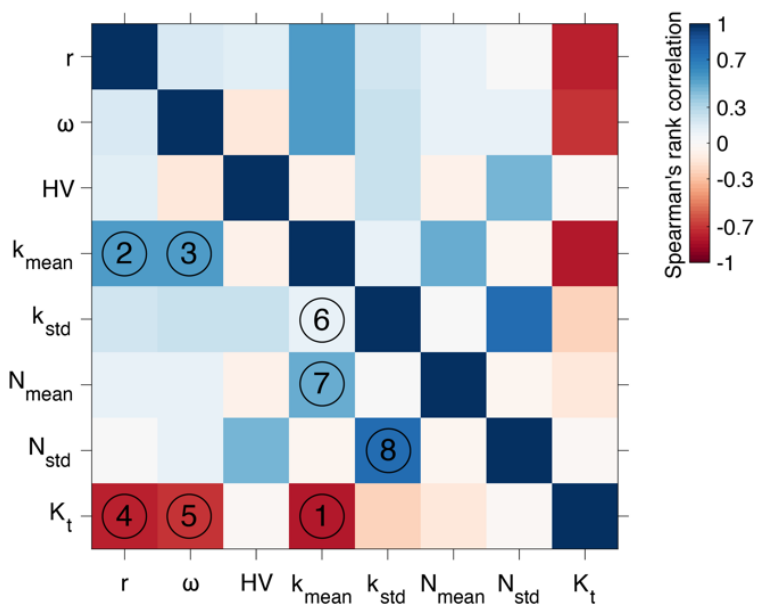

Figure 14. Correlation between maximum likelihood parameters and influencing factors based on (a) Pearson (linear) and (b) Spearman's (non-linear) rank correlation coefficient.

The main findings from the assessment of correlation coefficients are as follows:

- The highest correlation (marked by ' 1 ' in Figure 14) between two variables is observed between stress concentration factors and the mean slope exponents determined by bootstrapping $\left(\left|r_{\text {Pearson }}\right|=0.72\right.$ and $\left.\left|r_{\text {spearman }}\right|=0.79\right)$. In addition, moderate correlations are determined between the mean slope exponents and notch radius $\left(\left|r_{\text {Pearson }}\right|=0.37\right.$ and $\left.\left|r_{\text {Spearman }}\right|=0.55\right)$ as well as opening angle ( $\left|r_{\text {Pearson }}\right|=0.33$ and $\left.\left|r_{\text {Spearman }}\right|=0.56\right)$, marked by ' 2 ' and ' 3 ', respectively.

- Unsurprisingly, moderate to strong correlations are also observed for the relation between stress concentration factors, and either notch radius $\left(\left|r_{\text {Pearson }}\right|=0.48\right.$ and $\left.\left|r_{\text {Spearman }}\right|=0.77\right)$ or opening angle $\left(\left|r_{\text {Pearson }}\right|=0.65\right.$ and $\left.\left|r_{\text {Spearman }}\right|=0.71\right)$, marked by ' 4 ' and ' 5 ', respectively.

- The reason for the higher Spearman-type correlations for the aforementioned parameters is expected to be related to their non-linear interaction, which is expectedly better assessed using a non-linear type of correlation coefficient. 
- While there is a Pearson correlation (marked by ' 6 ') between the mean and scatter of the slope exponents $\left(\left|r_{\text {Pearson }}\right|=0.7\right)$, there is no such correlation according to Spearman's rank correlation. Assessing the results, it is found that the strong Pearson correlation is related to one outlier. This supports the assumption that a Pearson correlation coefficient is more prone to outliers.

- Also, a moderate correlation is observed between the means of the knee points and the means of the slope exponents $\left(\left|r_{\text {Pearson }}\right|=0.54\right.$ and $\left.\left|r_{\text {Spearman }}\right|=0.49\right)$ and a quite strong correlation between the standard deviations of both variables $\left(\left|r_{\text {Pearson }}\right|=0.65\right.$ and $\left.\left|r_{\text {Spearman }}\right|=0.76\right)$, marked by ' 7 ' and ' 8 ', respectively. The second correlation is thought to be systematically related to the general increase in scatter in fatigue test results with decreasing notch acuity.

In addition to the correlation matrixes, a symbolic regression was conducted with the same input data using the Python toolkit sklearn. As identified in the correlation matrices, the slope $k$ has a strong correlation to $K_{t}$ and can be expressed by equation 7 . The slope gets steeper with increasing stress concentration.

$$
k=6.6-\sqrt{K_{t}}
$$

In contrast, no meaningful and interpretable correlation between the position of the knee point and the geometric and material parameters of the specimens could be achieved. This result is also in line with the correlation matrices, Figure 14.

\section{Discussion}

A large number of artificially notched specimens differing with respect to the notch acuity, material strength and microstructural properties, were tested until fracture, leading to different fatigue characteristics. Overall, 26 test series including 351 specimens were considered in the analysis. For each test series, the material was characterized (geometry, misalignment and hardness measured) and the influence of misalignments caused by welding was quantified by means of the strain gauges. As a basis for the fatigue crack growth calculations, a parametric FE model was created and used to determine the actual stress profiles along the expected crack path for each specimen. Thereby, it was possible to model the specimens in the most accurate way including misalignment-induced secondary bending stresses.

For the majority of specimens, crack initiation was detected visually or per gauges showing a dependency of crack initiation duration on the notch acuity. Principally, fatigue cracks initiated early in case of crack-like notches, whereas the fraction of load cycles before crack initiation increased with decreasing notch stress range, as indicated in Figure 10(b).

The statistical evaluation of S-N curves with the maximum likelihood approach proved to be a good method to provide information on the S-N curve, i.e., its parameters knee point $N_{k}$, slope $k$ and the endurable stress at the knee point $\sigma_{n, a, k}$; however, the determined position of $N_{k}$ at the location of the smallest value of the support function is accompanied with uncertainties, especially in cases where the support function has not a pronounced minimum, see Figure 7, bottom right.

A measure of the accuracy of the values can be derived by bootstrapping the S-N data. With this approach, a standard deviation as measure of the accuracy can be assigned to each value. It must be mentioned that the bootstrapping might lead in some cases to unrealistic results that increase in number with the scatter of the S-N curve and the number or resamples. Therefore, extreme values, as they can be identified in Figure 13 by a small distribution width, should not be over-interpreted.

The coefficients of variation of the three parameters $k, N_{k}$ and $\sigma_{a, n, k}$ from bootstrapping show clearly that the values of the slope $k$ have the highest variation, followed by the ones of the knee point $N_{k}$; however, it has to noted that the value ranges are not directly comparable. A change in slope from, e.g., 5 to 6 is in terms of the endurable number of cycles small to a change of the knee point from $\log 10\left(N_{k}\right)=5$ to 6 , i.e., from $10^{5}$ to $10^{6}$.

Results in Section 5.1 suggest that the total fatigue life of notched specimens can rather accurately be predicted by a fracture mechanics approach; however, this requires comprehensive 
material data, including FCG curves and tensile properties for different weld zones, including the base metal and HAZ. As such data are rarely available, they can be estimated. In this study, only two experimental data sets on FCG curves were involved - for S355NL and S960QL steel grades, both related to the base metal. Subsequently, those FCG curves were used for other materials with similar strength properties and for other microstructural zones of the same steel grade. Another problem faced at the strength assessment of welded components is missing information on the local strength properties of the weld metal and HAZ. As a pragmatic solution, both the yield strength and the tensile strength were estimated in all cases, including the base metal, from the hardness measurements. Finally, a unique definition of an initial surface crack, referred to as short crack, was employed in all fracture mechanics calculations. Accordingly, an assumption of a semi-elliptical crack with the depth $a_{s c i}=0.5 \mathrm{~mm}$ and the length $2 c_{s c i}=1 \mathrm{~mm}$ was found to yield an optimal accuracy in predicting fatigue lives of all test series. An essential feature of sharply notched specimens is a high stress level at the notch root and, consequently, plastic deformations achieved for a considerable number of specimens analyzed. These effects were accounted for by means of a proper plasticity correction applied to the stress intensity factors.

The predicted fatigue lives associated with crack propagation, $N_{F C G, p r e}$, are in a good agreement with the total fatigue lives, $N_{f, \text { exp }}$, determined in the tests. For $77 \%$ of all specimens, the fracture mechanics approach yields $N_{F C G, p r e}<N_{f, \exp }$ (see Figure 11a) and, thus, allows for estimating the number of cycles until crack initiation. In the other cases, the fracture mechanics model results in a nonconservative lifetime prediction and, thus, in negative estimates of the lifetime until crack initiation, $N_{\text {sci,pre }}$. The latter conclusion holds for some of the specimens of the following six test series:

- Series 13: material S355J2+N, base metal, notch opening angle $\omega=0^{\circ}$.

- Series 5 and 6: material S355J2+N, HAZ, notch opening angle $\omega=0^{\circ}$ and $\omega=135^{\circ}$, respectively.

- Series 10 and 11: material S690QL, HAZ, notch opening angle $\omega=0^{\circ}$ and $\omega=135^{\circ}$, respectively.

- Series 24: material S355MC, HAZ, unnotched specimens, $\omega=180^{\circ}$.

For the test series $13, N_{F C G, p r e}$ and $N_{f, \text { exp }}$ are in a good agreement: all points are bounded by the 1:3 and 3:1 lines, and an approximately equal number of points are located above and below the 1:1 line. Hence, non-conservative lifetime prediction in this test series is mainly attributed to the experimental data scatter and the fact that the sharp notch leads to a very early crack initiation. For the other five test series, all with the crack position in the HAZ, the main reason for the non-conservative prediction is likely due to an inaccurate estimation of the respective FCG curves. For a better confidence of a fracture mechanics model, additional FCG tests are required on specimens extracted from the HAZ with different microstructure and strength properties.

In addition, multiple crack initiation was observed during fatigue testing for some specimens. These cracks coalesced in the following cycles and formed a longer crack. Similarly, some cracks did not initiate in the middle of the notch but closer to one of the edges. For such scenarios, deviations in prediction accuracy are inevitable. This also influences the crack propagation behavior and therefore leads to lower prediction accuracy.

Based on the statistical evaluation, it was possible to determine correlations between influencing factors and the shape of the S-N curves. Two different correlation coefficient types, linear Pearson and non-linear Spearman rank, were used, as it is known that some factors follow a non-linear relation. The highest correlation between two variables is observed between the stress concentration factor and the mean slope exponents determined by bootstrapping. In addition, moderate Spearman rank correlations are also determined between the mean slope exponent and the notch geometry represented by the notch radius as well as opening angle. Interestingly, there seems to be no effect on the mean and standard deviation of the bootstrapped knee point of the S-N curves. This is in contrast to former studies, e.g., by Hück et al. [40] who determined a logarithmic relation between the stress concentration factor and both the slope $k$ and the knee point $N_{k}$ of S-N curves for base materials. The results presented in the current study do not agree with the concept of normalized S$\mathrm{N}$ scatter bands by Haibach [5]. He argued that differences in slopes of S-N curves are related to the fact that for lower notch acuity a large part of fatigue tests performed at high stress ranges fall into 
the transition region from the high-cycle to the low-cycle fatigue regime. For plain specimens $\left(K_{t} \approx\right.$ $1)$, this effect is even more pronounced due to gross cyclic plastification at high stress ratios (corresponding to small number of cycles to failure $N_{f}<10^{5}$ cycles). As a considerable amount of test data for this study is based on test of high strength steels with number of cycles to failure above $10^{5}$ cycles, there is clear evidence that there is a relation between the slope of S-N curves and the notch acuity. In fact, this agrees with one conclusion presented by Hück et al. [40].

As mentioned in Section 2.2, the slope of welded joints is set to $k=3$ in most rules and recommendation. This assumption is in contradiction to the relationship identified in this work. Only BS 7608 [17] recommends a slightly shallower slope for weld details with low stress concentration factors; however, it should be noted, that the specimens considered here have only three weld characteristics, i) sharp notches, ii) typical notch opening angles and iii) typical microstructural properties in the area of crack initiation and crack propagation. Other characteristics that may have an influence on the course of the S-N curve such as residual stresses, a varying weld profile or inner weld imperfections are not considered. It can be assumed that the quality of the butt joints that build the experimental basis for the recommendation in rules and guidelines was not high, and the joints contained strong irregularities and, consequently, stress raisers.

In this investigation, no correlation between geometrical or metallurgical features and the knee point has been identified. This stands in contrast to some guidelines that correlate the knee point to the weld details but likely explains the circumstance, that there is no common agreement between all major guidelines. As for the knee point it has to be mentioned, that the specimens investigated in this work do show only some features of welded joints. A further re-analysis of (high-quality) fatigue data for welded joints needs to be performed, in which all relevant properties are well documented.

\section{Conclusions}

This study investigated the relationship between fatigue crack initiation and propagation in welded joints using artificially notched specimens with welded joints characteristics of different notch acuity (different radii and opening angle). From the statistical and numerical assessment of the experiments, the following conclusions are obtained:

- The fracture mechanics approach allows for a reasonable prediction of the total fatigue life. In the most cases, $77 \%$ of the specimens analyzed, this approach leads to conservative estimates of fatigue lives. For the rest $23 \%$ of the specimens, the fatigue life is overestimated by maximum a factor of 3. The assumption of an initial semi-elliptical crack with the depth of $a_{s c i}=0.5 \mathrm{~mm}$ and the length of $2 c_{s c i}=1 \mathrm{~mm}$ appeared to be a good compromise for all 26 test series. In the fracture mechanics calculations, plasticity deformations at the notch root need to be taken into account. This was achieved in this study by applying a plasticity correction to the stress intensity factors, based on the FAD approach. Non-conservative results and relatively large data scatter observed for some of the test series are believed to be partly attributed to assumptions related to fatigue crack growth curves and inaccuracies resulting from their smooth curve fitting. Additional inaccuracies may result from a simplified analysis approach assuming a single crack initiation site in the middle of the specimen thickness, thus ignoring possibilities of multiple crack initiation or crack initiation at the specimen edge. Both latter scenarios would result in a shorter fatigue life as compared to the model adopted in this study.

- For sharply notched specimens, the initiation phase is negligible and the total fatigue life is dominated by fatigue crack propagation. Therefore, the back calculation of the fatigue crack initiation phase, $N_{s c i}$, is subject to large errors. In contrast, such estimates of $N_{s c i}$ are shown to be rather accurate for mild notches.

- The bootstrapping of S-N data is a suitable statistical method to identify the accuracy of the evaluated S-N parameters and to determine statistically validated estimates for the slope $k$ and the knee point $N_{k}$ of S-N curves.

- Depending on the chosen correlation coefficient type, a moderate to almost strong correlation between applied notch stress range $\Delta \sigma_{\text {notch }}$ with the ratio between experimental cycles to short $N_{\text {sci,exp }}$ or long crack initiation $N_{l c i, \exp }$ and cycles to fracture $N_{f, \exp }$ were determined, Figure 10. 
In addition, the assessment supports the general understanding that the crack initiation portion dominates in the high-cycle fatigue regime, whereas the crack propagation stage dominates in the medium- and low-cycle fatigue regime, Radaj et al. [1] and Murakami [4].

- Using artificially notched specimens and statistical methods, it was shown that the slope $k$ but not the knee point $N_{k}$ of S-N curves correlates to the notch acuity, the latter being defined by the notch radius and notch opening angle, or the stress concentration factor.

Supplementary Materials: The following are available online at https://doi.org/10.5281/zenodo.6020696, Table: Dataset for this article

Author Contributions: Conceptualization, methodology, validation, formal analysis and investigation, M.B., J.B., C.F. and I.V.; software, M.B., J.B. and I.V.; data curation, all; visualization, M.B. and J.B.; writing-original draft preparation, all; writing - review and editing, all; funding acquisition, J.B. and I.V. All authors have read and agreed to the published version of the manuscript.

Funding: The Federal Ministry for Economic Affairs and Energy BMWi funded the work of J.B. and M.H. by the AiF e.V. (Arbeitsgemeinschaft industrieller Forschungsvereinigungen “Otto von Guericke" e.V.) under grant 20.366 BG.

Acknowledgments: M.B. would like to thank Franziska Rolof for helping with the specimens preparation.

Conflicts of Interest: The authors declare no conflict of interest.

\section{Appendix A}

Table A1. Results of the statistical evaluation of the S-N curves with maximum likelihood

\begin{tabular}{|c|c|c|c|c|c|c|c|c|}
\hline $\begin{array}{l}\text { Test } \\
\text { series }\end{array}$ & $\begin{array}{c}\text { Slope } \\
\boldsymbol{k}\end{array}$ & $\begin{array}{c}\text { Stress } \\
S_{k}\end{array}$ & $\begin{array}{c}\text { Knee point } \\
\qquad N_{k} \\
{\left[\times 1^{3}\right]}\end{array}$ & $\begin{array}{l}\text { Scatter } \\
1: T_{S}\end{array}$ & $\begin{array}{c}\text { Slope } \\
\boldsymbol{k}\end{array}$ & $\begin{array}{c}\text { Stress } \\
S_{k}\end{array}$ & $\begin{array}{c}\text { Knee point } \\
N_{k} \\
{\left[\times 1^{3}\right]}\end{array}$ & $\begin{array}{l}\text { Scatter } \\
1: T_{S}\end{array}$ \\
\hline & \multicolumn{4}{|c|}{$\begin{array}{c}\text { Maximum likelihood evaluation } \\
\text { with original data }\end{array}$} & \multicolumn{4}{|c|}{$\begin{array}{l}\text { Maximum likelihood evaluation } \\
\text { from bootstrapping (mean values) }\end{array}$} \\
\hline 1 & 3.11 & 91.7 & 501 & 1.11 & 3.12 & 92.0 & 504 & 1.10 \\
\hline 2 & 5.32 & 165.2 & 1,122 & 1.36 & 4.79 & 175.3 & 1,032 & 1.30 \\
\hline 4 & 4.03 & 160.9 & 501 & 1.06 & 4.03 & 161.0 & 503 & 1.05 \\
\hline 5 & 3.29 & 93.3 & 1,000 & 1.23 & 3.02 & 96.5 & 875 & 1.18 \\
\hline 6 & 4.54 & 149.0 & 1,000 & 1.14 & 4.57 & 147.5 & 1,197 & 1.12 \\
\hline 7 & 3.91 & 227.1 & 316 & 1.18 & 3.80 & 221.4 & 445 & 1.16 \\
\hline 8 & 4.54 & 155.7 & 794 & 1.08 & 4.41 & 159.4 & 720 & 1.06 \\
\hline 10 & 3.79 & 77.1 & 891 & 1.16 & 3.74 & 74.2 & 1,267 & 1.14 \\
\hline 11 & 3.28 & 130.3 & 398 & 1.35 & 3.22 & 127.4 & 716 & 1.31 \\
\hline 13 & 3.78 & 121.7 & 794 & 1.08 & 3.67 & 129.8 & 664 & 1.06 \\
\hline 14 & 3.49 & 502.7 & 251 & 1.24 & 3.15 & 505.3 & 233 & 1.22 \\
\hline 15 & 3.83 & 110.3 & 1,413 & 1.10 & 4.02 & 109.0 & 1,753 & 1.09 \\
\hline 16 & 1.14 & 454.9 & 200 & 1.23 & 2.48 & 453.5 & 233 & 1.20 \\
\hline 17 & 3.43 & 153.1 & 501 & 1.13 & 3.55 & 150.3 & 611 & 1.11 \\
\hline 18 & 3.24 & 109.7 & 3,981 & 1.22 & 3.02 & 120.7 & 2,985 & 1.18 \\
\hline 19 & 4.78 & 193.2 & 2,239 & 1.09 & 4.75 & 192.0 & 2,429 & 1.08 \\
\hline 20 & 4.99 & 155.7 & 3,981 & 1.05 & 4.95 & 158.0 & 3,704 & 1.05 \\
\hline 21 & 5.33 & 199.6 & 3,162 & 1.08 & 5.28 & 200.1 & 3,120 & 1.07 \\
\hline 22 & 3.80 & 254.3 & 708 & 1.10 & 4.00 & 251.9 & 891 & 1.07 \\
\hline 23 & 2.94 & 181.5 & 1,259 & 1.14 & 3.12 & 179.1 & 1,909 & 1.11 \\
\hline 24 & 5.79 & 339.6 & 8,913 & 1.34 & 5.74 & 352.8 & 7,816 & 1.27 \\
\hline 25 & 7.98 & 249.0 & 3,981 & 1.15 & 6.71 & 261.6 & 2,646 & 1.11 \\
\hline 26 & 1.74 & 179.7 & 398 & 1.21 & 3.16 & 173.4 & 1,025 & 1.16 \\
\hline 27 & 5.00 & 548.8 & 116 & 1.29 & 8.05 & 520.7 & 1,883 & 1.16 \\
\hline 28 & 6.37 & 251.3 & 10,000 & 1.41 & 5.15 & 284.3 & 7,385 & 1.31 \\
\hline
\end{tabular}




\begin{tabular}{l|l}
282 & 1.36
\end{tabular}

6.18

302.9

4,879 1.25

\section{References}

1. Radaj, D.; Sonsino, C.M.; Fricke, W. Fatigue assessment of welded joints by local approaches, 2nd ed.; Woodhead publishing: Cambridge, 2006.

2. Baumgartner, J.; Waterkotte, R. Crack initiation and propagation analysis at welds - assessing the total fatigue life of complex structures. Materialwissenschaft und Werkstofftechnik 2015, 46, 123-135, doi:10.1002/mawe.201400367.

3. Fischer, C.; Fricke, W. Effect of the stress distribution in simple welded specimens and complex components on the crack propagation life. International Journal of Fatigue 2016, 92, 488-498, doi:10.1016/j.ijfatigue.2016.02.041.

4. Murakami, Y. Metal fatigue: effects of small defects and nonmetallic inclusions, 2nd ed.; Academic Press: 2019; doi.org/10.1016/C2016-0-05272-5.

5. Haibach, E. Betriebsfestigkeit: Verfahren und Daten zur Bauteilauslegung, 3rd ed.; Berlin, Heidelberg, New York: Springer-Verlag: 2006.

6. Socie, D.F.; Marquis, G.B. Multiaxial fatigue; SAE International: Warrendale, PA, 1999.

7. Fiedler, M.; Wächter, M.; Varfolomeev, I.; Vormwald, M.; Esderts, A. Rechnerischer Festigkeitsnachweis unter expliziter Erfassung nichtlinearen Werkstoffoerformungsverhaltens für Bauteile aus Stahl, Stahlguss und Aluminiumknetlegierungen; VDMA Verlag: Frankfurt am Main, 2019.

8. Forschungskuratorium Maschinenbau (FKM). Analytical Strength Assessment of Components: FKM Guideline. 6th ed.; VDMA: Frankfurt/Main, 2012.

9. Forman, R.; Shivakumar, V.; Mettu, S.; Newman, J. Fatigue crack growth computer program NASGRO version 3.0. Reference Manual, NASA JSC-22267B 2000.

10. Paris, P.C.; Bucci, R.J.; Wessel, E.T.; Clark, W.G.; Mager, T.R. Extensive Study of Low Fatigue Crack Growth Rates in A533 and A508 Steels. In Stress Analysis and Growth of Cracks: Proceedings of the 1971 National Symposium on Fracture Mechanics: Part 1, ASTM International: 1972; Vol. Part 1, pp. 141-141136, doi:10.1520/stp34119s.

11. Dowling, N.; Begley, J. Fatigue crack growth during gross plasticity and the J-integral. In Mechanics of crack growth, ASTM International: 1976.

12. Wüthrich, C. The extension of the J-integral concept to fatigue cracks. Int J Fracture 1982, 20, R35-R37.

13. McClung, R.C.; Chell, G.G.; Lee, Y.D.; Russel, D.A.; Orient, G.E. Development of a practical methodology for elastic-plastic and fully plastic fatigue crack growth; ASTM International: Marshall Space Flight Center, 1999.

14. Zerbst, U.; Madia, M.; Hellmann, D. An analytical fracture mechanics model for estimation of S-N curves of metallic alloys containing large second phase particles. Eng Fract Mech 2012, 82, 115-134, doi:10.1016/j.engfracmech.2011.12.001.

15. British Energy Generation Limited. R6, assessment of the integrity of structures containing defects, Revision 4. 2001.

16. Baumgartner, J. Review and considerations on the fatigue assessment of welded joints using reference radii. International Journal of Fatigue 2017, 101, 459-468, doi:10.1016/j.ijfatigue.2017.01.013.

17. British Standards Institution. BS 7608:2014+A1:2015: Guide to fatigue design and assessment of steel products. BSI London: 2014. 
18. European Committee for Standardization. EN 1993-1-9:2005 - Eurocode 3: Design of Steel Structures Part 1-9: Fatigue. Brussels, BE, 2005.

19. Hobbacher, A.F. Recommendations for Fatigue Design of Welded Joints and Components, 2nd ed.; Springer International Publishing Switzerland: 2016; 10.1007/978-3-319-23757-2.

20. American Welding Society. AWS D1.1:2010 Structural Welding Code-Steel. 2010.

21. Japanes Society of Steel Construction. Fatigue design recommendations for steel structures; Japanese Society of Steel Construction: 1995.

22. Renken, F.; von Bock und Polach, R.U.F.; Schubnell, J.; Jung, M.; Oswald, M.; Rother, K.; Ehlers, S.; Braun, M. An algorithm for statistical evaluation of weld toe geometries using laser triangulation. International Journal of Fatigue 2021, 149, doi:10.1016/j.ijfatigue.2021.106293.

23. DNV GL AS. DNVGL-RP-C203: Recommended practice for Fatigue Design of offshore steel structures. Høvik, Norway, 2016.

24. British Standards Institution. BS 7910:2013+A1:2015 Guide to methods for assessing the acceptability of flaws in metallic structures. London, UK, 2015.

25. Bowness, D.; Lee, M.M.K. Fracture mechanics assessment of fatigue cracks in offshore tubular structures; 2002.

26. Fischer, C.; Fricke, W.; Rizzo, C.M. Fatigue tests of notched specimens made from butt joints at steel. Fatigue Fract Eng M 2016, 39, 1526-1541, doi:10.1111/ffe.12473.

27. Baumgartner, J. Schwingfestigkeit von Schweißverbindungen unter Berücksichtigung von Schweißeigenspannungen und Größeneinflüssen; Fraunhofer Verlag: Stuttgart, 2014.

28. International Standards Organisation. ISO 6507-1:2005 Metallic materials - Vickers hardness test Part 1: Test method. Geneva, Switzerland, 2005.

29. Störzel, K.; Baumgartner, J. Statistical evaluation of fatigue tests using maximum likelihood. Materials Testing 2021, 63, 714-720, doi:10.1515/mt-2020-0116.

30. Sonsino, C. Course of SN-curves especially in the high-cycle fatigue regime with regard to component design and safety. International Journal of Fatigue 2007, 29, 2246-2258, doi:10.1016/j.ijfatigue.2006.11.015.

31. Spindel, J.E.; Haibach, E. The method of maximum likelihood applied to the statistical analysis of fatigue data. International Journal of Fatigue 1979, 1, 81-88, doi:10.1016/0142-1123(79)90012-4.

32. Braun, M.; Müller, A.M.; Milaković, A.-S.; Fricke, W.; Ehlers, S. Requirements for stress gradient-based fatigue assessment of notched structures according to theory of critical distance. Fatigue Fract Eng M 2020, 43, 1541-1554, doi:10.1111/ffe.13232.

33. Zerbst, U. Analytische bruchmechanische Ermittlung der Schwingfestigkeit von Schweißverbindungen (IBESSA3); Bundesanstalt für Materialforschung und -prüfung (BAM): Berlin, 2016.

34. Wang, X.; Lambert, S.B. Stress intensity factors for low aspect ratio semi-elliptical surface cracks in finite-thickness plates subjected to nonuniform stresses. Eng Fract Mech 1995, 51, 517-532, doi:10.1016/0013-7944(94)00311-5.

35. Sattari-Far, I.; Dillström, P. Local limit load solutions for surface cracks in plates and cylinders using finite element analysis. International Journal of Pressure Vessels and Piping 2004, 81, 57-66, doi:10.1016/j.ijpvp.2003.11.015.

36. Fett, T.; Munz, D. Stress intensity factors and weight functions for one-dimensional cracks; Kernforschungszentrum Karlsruhe, Germany: 1994.

37. Willoughby, A.A.; Davey, T.G. Plastic Collapse in Part-Wall Flaws in Plates. In Fracture Mechanics: Perspectives and Directions (Twentieth Symposium), Wei, R.P., Gangloff, R.P., Eds. ASTM International: Philadelphia, 1989; Vol. ASTM STP 1020, pp. 390-390-320, doi:10.1520/stp18834s. 
38. Pavlina, E.J.; Van Tyne, C.J. Correlation of Yield Strength and Tensile Strength with Hardness for Steels. Journal of Materials Engineering and Performance 2008, 17, 888-893, doi:10.1007/s11665-008-9225-5.

39. Caruso, J.C.; Cliff, N. Empirical Size, Coverage, and Power of Confidence Intervals for Spearman's Rho. Educational and Psychological Measurement 1997, 57, 637-654, doi:10.1177/0013164497057004009.

40. Hück, M.; Thrainer, L.; Schütz, W. Berechnung von Wöhlerlinien für Bauteile aus Stahl, Stahlguß und Grauguß: synthetische Wöhlerlinien, 3rd ed.; Stahleisen: 1983. 